\title{
Análise Comparativa da Emissão de Gases de Efeito Estufa entre Práticas de Reutilização e de Aquisição de Novos Equipamentos de TI
}

\author{
Yves Wanderley Estanislau da Costa Netto \\ Pontifícia Universidade Católica do Rio Grande do Sul - PUCRS \\ yves.costa@gmail.com
}

\section{Leonardo Rocha de Oliveira}

Pontifícia Universidade Católica do Rio Grande do Sul - PUCRS

leorochadeoliveira@gmail.com

\section{Carlos Vicente de Souza}

Pontifícia Universidade Católica do Rio Grande do Sul - PUCRS

souzacv@pucrs.br

\section{Resumo}

A reutilização tem sido indicada como prática para atenuar o impacto de equipamentos de TI ao meio ambiente. No entanto, a extensão no tempo de uso pode adiar a adoção de recursos mais modernos e com maior eficiência energética. O objetivo deste trabalho é analisar a reutilização como prática para a mitigação de emissões de gases de efeito estufa (GEE) no ciclo de vida de equipamentos de TI. O trabalho foi desenvolvido com dados coletados em três anos de operação do Centro Social Marista (CESMAR) de Porto Alegre. Resultados indicam que a reutilização de computadores e monitores auxilia na mitigação de emissões de GEE, e que a geração de energia, a partir de fontes renováveis, tem papel importante em reduzir emissões na fase de uso. As conclusões indicam que a reutilização de equipamentos de TI é uma prática que deve ser realizada sempre que possível no Brasil.

Palavras-chave: Gestão do Ciclo de Vida, Reutilização de Equipamentos de TI, Mitigação de Gases de Efeito Estufa

\begin{abstract}
Reutilization is a practice widely indicated as capable to lessen the impact of IT equipment to the environment. However, the extent of usage time may delay the adoption of newer equipment with improved energy efficiency. The objective of this work is to analyze the reutilization as a practice for mitigating greenhouse gases (GHG) emissions along the life cycle of computers and monitors. The
\end{abstract}


study was carried out using data collected along 3 years of operation of the Marist Social Centre (CESMAR) in Porto Alegre. Results indicate that reutilization of IT equipment contributes to mitigating GHG emissions, and electricity generated from renewable sources has an important role for reducing emissions at the use stage. Conclusions show that reutilization of IT equipment is a practice that should be performed whenever is possible in Brazil.

Keywords: Life Cycle Management, IT Equipment Reuse, Greenhouse Gases Mitigation

\section{Introdução}

Equipamentos de Tecnologia da Informação (TI) necessitam de energia e recursos naturais, que por sua vez têm um correspondente impacto ambiental ao longo de todo o seu ciclo de vida. Dentre as consequências danosas para o meio ambiente, destaca-se a emissão de gases de efeito estufa (GEE). A extensão no tempo de uso destes equipamentos é recomendação usual para mitigar o impacto ambiental causado ao meio ambiente pelas emissões de GEE (MINGAY, 2007). A rápida obsolescência e o continuo aumento na demanda por recursos de TI nas organizações e para uso pessoal, contribuem para o crescimento das emissões de GEE causados por equipamentos eletrônicos (TEEHAN e KANDLIKAR, 2012).

A Avaliação de Ciclo de Vida (ACV) de um produto permite estimar a quantidade de energia demandada desde a extração de matéria prima para a fabricação até o descarte final. Dessa forma, a ACV proporciona a qualificação e quantificação dos impactos ambientais correspondentes (REBITZER et al., 2004). A reutilização de produtos, dentre eles os equipamentos de TI, promove o aumento no tempo de vida e contribui para a redução da intensidade energética ao longo do ciclo de vida (FUJII; YAMAGIWA e UEHARA, 2011). Entretanto, o posicionamento de marketing das empresas fabricantes de equipamentos de TI geralmente segue a diretriz da obsolescência planejada, ao reduzir continuamente o ciclo de vida de seus produtos, e estimular no consumidor a necessidade em adquirir novos modelos, mesmo que os atuais ainda estejam com capacidade de atender aos objetivos de negócio (GUILTINAN, 2009).

Xavier e Corrêa (2013) assinalam que os produtos eletroeletrônicos, apesar de necessitarem de menor quantidade de material por unidade, agregam uma diversidade de materiais ao longo do seu processo produtivo. A extensão no tempo de uso dos equipamentos dentro das organizações ou externamente, é uma das recomendações para reduzir o impacto ambiental da TI (GARTNER, 2007). Murugesan (2008) aponta que a extensão no tempo de uso de equipamentos de informática contribui para a redução da pegada ecológica causada pela fabricação e descarte dos eletrônicos desses produtos. Tal fato adquire relevância crescente, se estima que até 2020 a indústria de TI responderá por 3\% das do total das emissões de GEE na atmosfera (BOCALLETI; LÖFFLER e OPPENHEIM, 2008).

O aquecimento global é causado pelo acúmulo de gases que não são transparentes à radiação térmica, atuando como um cobertor ao redor da Terra e fazendo com que perca menos calor para o espaço. Dessa forma, provoca o aquecimento analogamente a uma estufa, utilizada para permitir o crescimento de vegetais e flores fora das estações (GOLDEMBERG e LUCON, 2011). A comunidade científica discute exaustivamente a origem do aumento do fenômeno, porém evidências apontam para a existência de uma relação entre o uso intensivo de combustíveis fósseis após a revolução industrial, e o aumento dos níveis de $\mathrm{CO}_{2}$ (SINGH, 2009).

$\mathrm{O}$ artigo tem como objetivo, analisar a reutilização de equipamentos de TI como prática para a mitigação de emissões de GEE. Para atingir este objetivo foi estudado o Polo Marista de Formação Tecnológica. O Polo Marista, localizado na cidade de Porto Alegre, é um complexo do Centro Social Marista (CESMAR) onde são desenvolvidos diversos projetos sociais. O recondicionamento de equipamentos de TI doados pela comunidade auxilia na formação técnica profissionalizante de jovens em vulnerabilidade social, na inclusão digital e promove a adoção de práticas sustentáveis (MC, 2012). 
Na ocasião da terceira Conferência das Partes (COP3) em 1997 foi assinado o Protocolo de Quioto. Este acordo foi negociado pela Organização das Nações Unidas (ONU) com o propósito de fixar prazos aos países signatários para a redução de 5,2 \% de suas emissões de gases em relação aos níveis registrados em 1990. O protocolo possibilitou a criação de mecanismos de redução de gases de efeito estufa (GEE) para o envolvimento de países desenvolvidos e signatários do Anexo I. O acordo fixou metas a serem atingidas pelos países, e vigorou entre os anos de 2008 e 2012 (MARQUES et al., 2010).

Em 2012, na Convenção-Quadro das Nações Unidas sobre Mudanças Climáticas, que teve como sede a cidade de Doha no Catar, novos compromissos foram acordados e vários artigos do protocolo foram revistos e ampliados. A extensão do Protocolo de Quioto compreende um novo período, que se estende de 01/01/2013 a 31/12/2020 (CHEN et al., 2013).

A unidade de medida utilizada para equiparar os diferentes GEE na mesma base relativa a uma unidade de dióxido de carbono $\left(\mathrm{CO}_{2}\right)$ é o $\mathrm{CO}_{2}$ equivalente $\left(\mathrm{CO}_{2}\right.$ eq. $)$. Os GEE contemplados no protocolo de Quioto possuem diferentes Potenciais de Aquecimento Global (PAG) para cada horizonte temporal (SEIFFERT, 2013). Por exemplo, considerando o horizonte temporal de 100 anos, o metano $\left(\mathrm{CH}_{4}\right)$ possui um PAG 21 vezes maior que o $\mathrm{CO}_{2}$. Ou seja, uma tonelada de $\mathrm{CH}_{4}$ emitido ao longo de 100 anos aprisiona 21 vezes mais calor do que uma de $\mathrm{CO}_{2}$ no mesmo período (SMITH e WIGLEY, 2000).

Uma tonelada de $\mathrm{CO}_{2}$ corresponde a um crédito de carbono (SEIFFERT, 2013). O Protocolo de Quioto determina três mecanismos pelos quais os países podem adquirir estes créditos, que são:

- Mecanismo de implementação conjunta (MIC) - permitem que países desenvolvidos e signatários do Anexo I, com limitações para emissões de GEE, implementem projetos conjuntos para redução. Dessa forma, países que patrocinam os projetos recebem créditos de emissões, conhecidos como Unidade de Redução de Emissões (URE) (HEPBURN, 2007).

- Mecanismo de Desenvolvimento Limpo (MDL) - possibilitam que países desenvolvidos, com limitações para emissões de GEE, custeiem projetos conjuntos com países em desenvolvimento, aproveitando a mão de obra mais barata e obtendo as Reduções Certificadas de Emissões (RCEs) (MARQUES et al., 2010).

- Mecanismo de mercado de emissões (MME) - permite que países desenvolvidos e signatários do Anexo I possam vender ou comprar unidades de crédito pelo carbono não emitido, podendo assim atingir suas metas de redução ou receber fundos como troca pelos créditos correspondentes às emissões permitidas que deixarem de utilizar (HEPBURN, 2007).

Existem ainda os Mercados Voluntários (MV), cujas regras não são regidas, ou não se relacionam, com as metas e/ou mecanismos estabelecidos no Protocolo de Quioto (BMFBOVESPA, 2013). Uma das vantagens dos MV é permitir a implementação de projetos de mitigação de GEE em pequenas comunidades, que de outra forma não teriam esse benefício. Nesse aspecto, adquirem um papel ainda mais destacado do que projetos de MDL, na promoção do desenvolvimento sustentável (HEPBURN, 2007). Segundo Seiffert (2013) o principal mercado voluntário é a Bolsa do Clima de Chicago, que se posiciona como uma alternativa para a negociação através dos mecanismos definidos pelo Protocolo de Quioto. A principal vantagem desse mecanismo é permitir a certificação dos créditos de carbono sem que haja a necessidade de um projeto MDL aprovado junto a ONU.

\section{Impacto Ambiental no Ciclo de Vida de Equipamentos de TI}

Segundo Saaksvuori e Immonen (2008), a Gestão do Ciclo de Vida (GCV) de um produto permite controlar e dirigir o processo de criação, manuseio, distribuição e armazenamento das informações relacionadas aos produtos. Sudarsan et al. (2005) apontam que a GCV provê apoio ao longo do ciclo de vida do produto, desde o conceito inicial até o descarte. A GCV é considerada como a adaptação do conceito biológico do ciclo de vida para o contexto atual das práticas de negócios com o objetivo em gerir de forma completa todo o ciclo de vida dos produtos e serviços de uma organização com a finalidade em alcançar uma forma sustentável de consumo e produção (UNEP, 2007).

Xavier e Corrêa (2013) assinalam que a avaliação do ciclo de vida (ACV) permite uma visão abrangente e integrada das diversas etapas da vida útil de um produto, e complementam que também possibilita avaliar o impacto ambiental da (i) extração, (ii) composição e processamento de materiais, 
(iii) consumo energético e (iv) gestão de resíduos. Baumann e Tillman (2004) apontam que qualificação e quantificação dos recursos utilizados e das emissões de um produto ao longo das etapas que constituem seu ciclo de vida, permite identificar as informações correspondentes para estimar o seu impacto ambiental. Klopffer e Heirinch (2002) assinalam que a GCV é um conceito, enquanto a ACV é uma ferramenta.

Estudos a respeito da quantidade de energia utilizada ao longo do ciclo de vida de computadores e monitores apresentam diferentes conclusões a respeito do impacto e da fase responsável pela maior parte das emissões de GEE (TEEHAN e KANDLIKAR, 2012). A dificuldade em coletar dados e a falta de transparência têm sido apontadas como barreiras para avaliar e comparar o consumo de energia ao longo do ciclo de vida de produtos eletrônicos (HOPKINSON e JAMES, 2011). Goldemberg e Lucon (2011, p. 112) assinalam que "A forma com que a energia é produzida e utilizada é a causa de muitos dos impactos ambientais que testemunhamos".

Hopkinson e James (2011) indicam que as fases de produção e uso são responsáveis pela maior parte das emissões ao longo do ciclo de vida de equipamentos de TI. Para a fase de uso, as emissões refletem a forma com que a energia elétrica é gerada e distribuída no sistema da região, bem como o consumo de energia e o tempo de operação dos equipamentos. Na fase de produção as emissões refletem o consumo de energia e recursos naturais, desde a extração da matéria prima até a finalização do produto (MURUGESAN, 2008). De acordo com os pesquisadores referenciados, a parcela de emissões relativas ao transporte e descarte dos equipamentos de TI é muito reduzida ao comparar-se com as emissões das fases de produção e uso (SOCOLOF, OVERLY e GEIBIG, 2005; HOPKINSON e JAMES, 2009). Na Figura 1 verifica-se o modelo do ciclo de vida e o procedimento da ACV.

\section{MODELO DO CICLO DE VIDA PROCEDINENTO DA AVALIAÇÃO DO CICLO DE VIDA}

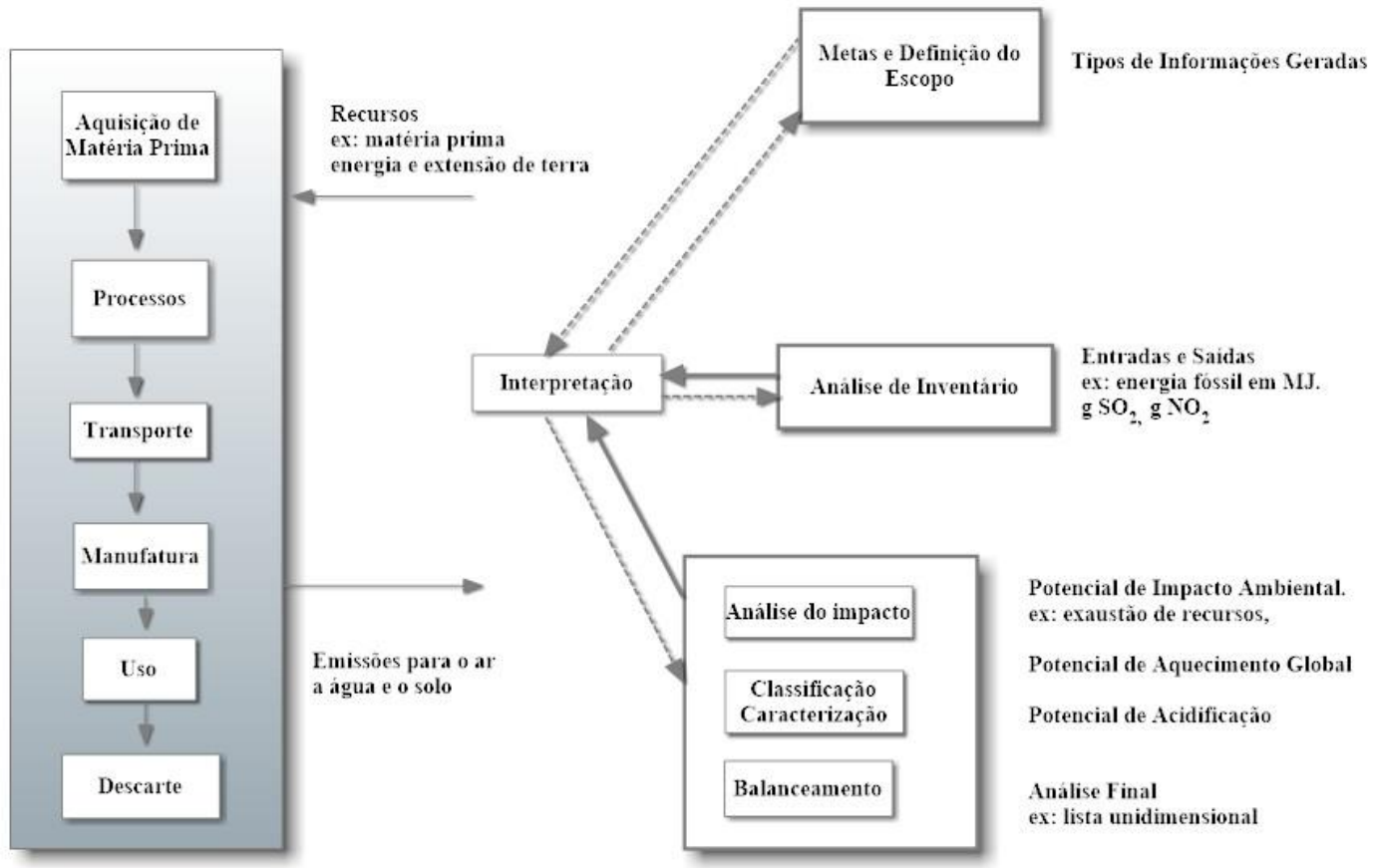

Figura 1 - Modelo do Ciclo de Vida e Procedimento de Avaliação do Ciclo de Vida. Fonte: Baumann e Tillman (2004, p.20).

Pickavet et al. (2008) assinalam que um PC, mesmo antes de ser ligado pela primeira vez, necessita de diversas fontes de energia, o que implica que sua produção seja responsável por uma parcela considerável do consumo de energia e recursos ao longo do seu ciclo de vida. Mais especificamente, os autores indicam que a fabricação das placas de circuitos integrados presentes nesse tipo de produto é responsável por grande parte das emissões totais dos eletrônicos, apesar de sua massa reduzida (TEEHAN e KANDLIKAR, 2013).

Ciceri, Gutowsky e Garetti (2012) indicam que a produção de semicondutores é apontada como a maior responsável pelo uso de energia na fabricação de um computador e estimaram que $95 \%$ 
do consumo de energia nessa fase é devido à fabricação de microprocessadores. Tal fato se torna mais complexo, na medida em que a diversidade de processos produtivos envolvidos na fabricação destes produtos inviabiliza a padronização da ACV (XAVIER e CORRÊA, 2013). Deng, Babbit e Williams (2011) indicam que os fatores determinantes para realizar a avaliação do ciclo de vida de computadores podem ser qualitativamente distintos na comparação com produtos de menor complexidade tecnológica, tal como refrigeradores ou aparelhos de ar condicionado. A Figura 2 apresenta uma comparação da utilização de energia nas fases de uso e produção de alguns equipamentos de TI, em comparação com resultados da indústria automotiva e da construção civil (WILLIAMS, 2011).

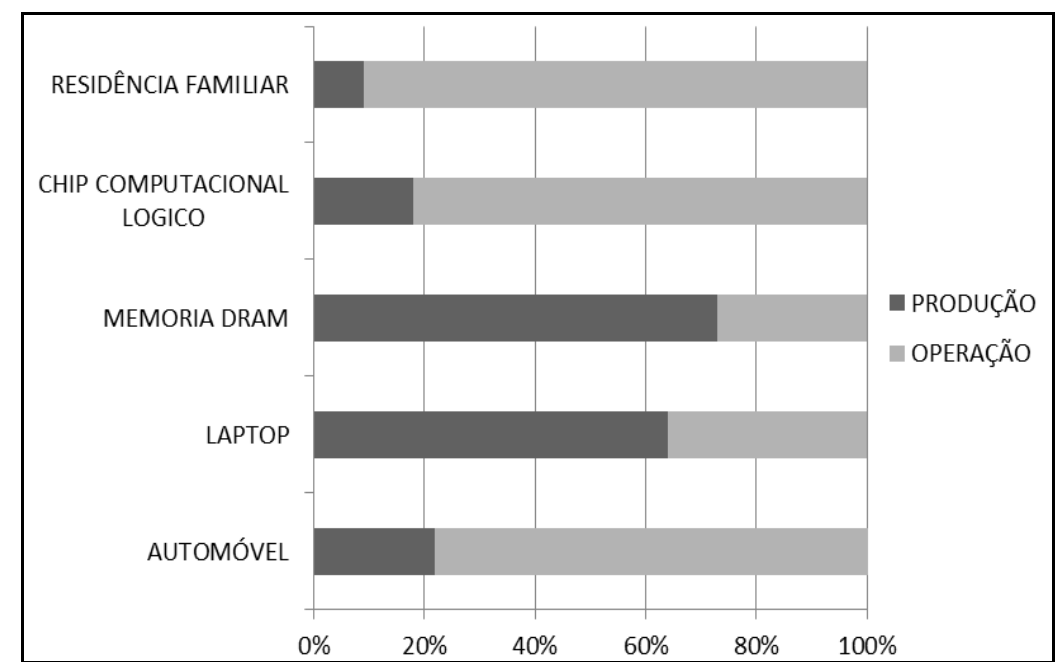

Figura 2 - Comparativo de consumo de energia para produção e uso entre produtos de TI, automotivos e construção civil.

Fonte: Williams (2011, p. 356)

Quanto à fabricação de monitores LCD, o trabalho de Prather e Hsu (2008) indica que os gases $\mathrm{SF}_{6}$ e $\mathrm{NF}_{3}$ representam uma parcela significativa do total de emissões resultantes. $\mathrm{O}$ trabalho destaca que o potencial de aquecimento global do $\mathrm{SF}_{6}$ relativo no horizonte temporal de 100 anos é 22.800 vezes maior do que o do $\mathrm{CO}_{2}$. $\mathrm{O} \mathrm{SF}_{6}$ é considerado o gás com maior potencial de aquecimento global (UNFCCC, 2013). Ainda, $\mathrm{o} \mathrm{NF}_{3}$ tem potencial de aquecimento global 17.200 vezes maior que $\mathrm{o}$ do $\mathrm{CO}_{2}$ (PRATHER; HSU, 2008), entretanto, não consta na pauta dos acordos internacionais de mitigação de GEE. No entanto, o $\mathrm{NF}_{3}$ é contabilizado na base de dados Ecoinvent (2013) na composição do total de emissões para a manufatura de monitores LCD. Estima-se que o potencial de aquecimento global de um monitor LCD, no horizonte temporal de 100 anos, seja até $140 \%$ maior do que um monitor CRT (HOPKINSON e JAMES, 2011). A Figura 3 apresenta uma comparação entre as emissões nas fases do ciclo de vida dos monitores CRT e LCD. Verifica-se que o uso do $\mathrm{SF}_{6}$ e $\mathrm{NF}_{3}$ influi na maior quantidade de emissões para a fase de extração de materiais e produção, enquanto nos monitores CRT, a fase de uso tem maior preponderância. 


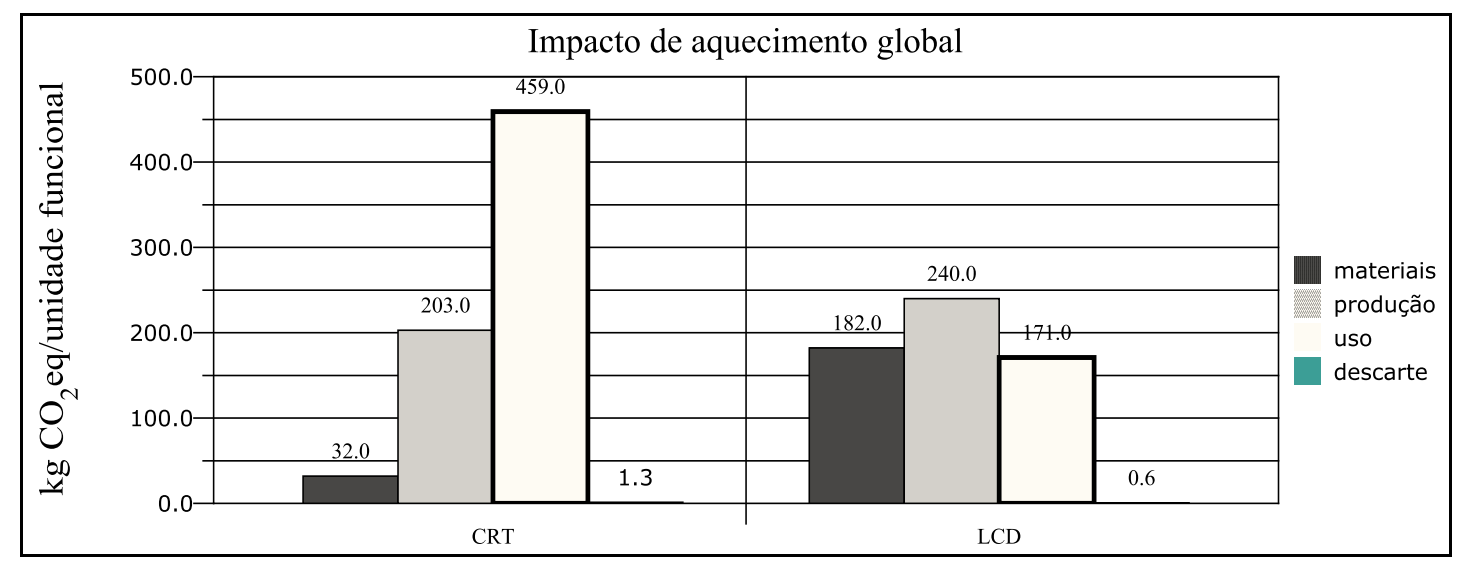

Figura 3 - Impacto de Aquecimento Global de Monitores CRT x LCD

Fonte: Socolof; Overly e Geibig (2005, p.1290)

A quantidade de emissões depende também da matriz energética de diferentes locais e países, os quais apresentam variações nas quantidades de uso de fontes não renováveis para geração de energia. Por exemplo, um país que usa predominantemente o carvão para gerar eletricidade na sua região é responsável por maior quantidade de emissões do que outro que utiliza preponderantemente matrizes renováveis, como por exemplo, as hidrelétricas (GOLDEMBERG e LUCON, 2011). Portanto, as emissões correspondentes à utilização de um equipamento dependem da sua potência real e da origem da energia elétrica consumida. O Sistema Interligado Nacional (SIN) engloba 97,8\% da geração de energia elétrica no país. O SIN é administrado pelo Operador Nacional do Sistema (ONS), que controla as operações de geração e transmissão de energia elétrica (PORTAL BRASIL, 2013). Segundo informação do Ministério da Ciência, Tecnologia e Inovação (MCTI):

Os fatores de emissão médios de $\mathrm{CO}_{2}$ a serem utilizados em inventários têm como objetivo estimar a quantidade de $\mathrm{CO}_{2}$ associada a uma geração de energia elétrica determinada. [...] Nesse sentido, ele deve ser usado quando o objetivo for quantificar as emissões da energia elétrica que está sendo gerada em determinado momento. Ele serve, portanto, para inventários em geral, corporativos ou de outra natureza.

A Empresa de Pesquisa Energética (EPE) indica que, em 2011, houve um aumento em 2,5\% em fontes renováveis no Brasil, totalizando 88,9\% (MCTI, 2013). A matriz de energia elétrica brasileira é uma das mais diversificadas e limpas do mundo, sendo composta por uma parcela significativa de fontes renováveis, com destaque para a energia hidrelétrica. Em março de 2013, a hidrelétrica correspondia a 68,9\% do total produzido no Brasil (MCTI, 2013).

O balanceamento entre as fontes renováveis e não renováveis varia na medida em que a demanda interna aumenta em relação à capacidade das hidrelétricas. Esse fator exige um aumento da produção nas termoelétricas e consequentemente da utilização de combustíveis fósseis para a produção de energia elétrica para o sistema (GOLDEMBERG e LUCON, 2011). No ano de 2011, a proporção de geração de energia elétrica por fontes renováveis no Brasil totalizou 88,9\%, e no ano de 2012 diminuiu para $84,9 \%$. Entretanto, esse resultado é significativamente superior aos dos demais países da Organização para a Cooperação e Desenvolvimento Econômico (OCDE) em 2010, a qual aponta que a média mundial foi de 19,7\% (EPE, 2013). Já em 2012 o total de fontes não renováveis para geração de energia pelas termoelétricas totalizou 69,6\% (EPE, 2013).

A partir do ano de 2006, o MCTI atualiza os fatores de emissão de $\mathrm{CO}_{2}$, no Brasil na razão de toneladas de $\mathrm{CO}_{2}$ por megawatts hora $\left(\mathrm{TCO}_{2} / \mathrm{MWh}\right)$, o que torna possível estimar as emissões resultantes do uso da energia elétrica proveniente do Sistema Interligado Nacional em um determinado mês. É possível também estimar a média de emissões anuais através do Fator Médio Anual (MCTI, 2013). O consumo de energia total na fase de uso pode ser estimado por três fatores combinados: os hábitos de uso individuais, a potência demandada pelo equipamento e seu tempo de vida útil do equipamento (YAO et al., 2011). Existe ainda um quarto fator que corresponde ao modo de operação do sistema instalado. Em geral, estudos sobre a avaliação do ciclo de vida de equipamentos de TI 
apontam as fases de produção e uso como as que mais consomem recursos naturais e energia. Entretanto há divergências sobre qual das duas provoca o maior impacto quanto à emissão em $\mathrm{CO}_{2} \mathrm{eq}$. (HOPKINSON e JAMES, 2011), tal como sobre o momento ideal para substituição, forma de reciclagem e logística reversa de equipamentos de TI.

Especificamente em relação ao uso de recursos de TI, estima-se que entre 2008 e 2020 o crescimento da demanda energética passará de $168 \mathrm{GW}$ para $430 \mathrm{GW}$ (PICKAVET et al., 2008). De forma análoga, existem previsões de que até 2020 o aumento das emissões do setor deve atingir 1,54 $\mathrm{GtCO}_{2}$ eq. ao ano, o que deve representar 3\% do total das emissões no planeta (BOCCALETTI; LÖFFLER e OPPENHEIM, 2008). Estas emissões correspondem à energia e aos recursos naturais consumidos desde a extração da matéria prima até a finalização do produto.

No caso da substituição, a definição do momento ideal geralmente considera dois principais aspectos: (i) o custo de aquisição de novos equipamentos e (ii) o custo de recondicionamento e reutilização dos recursos existentes. A queda acentuada no preço das peças e a rapidez na evolução tecnológica têm levado a um intenso dinamismo da indústria de TI e o aumento na eficiência energética dos equipamentos se tornou fator chave na redução do consumo de energia elétrica na fase de uso (MURUGESAN, 2008).

Teehan e Kandlikar (2012) indicam que existem poucos dados para que se possa estimar o tempo ideal para substituição em relação ao adicional proporcionado pelo reuso. No entanto, a reutilização de recursos de TI pode aumentar o consumo de energia elétrica, pois a tendência é de que novos equipamentos sejam mais eficientes para atender aos objetivos de negócios, ao mesmo tempo em que utilizam menos energia. Quando a utilização de energia elétrica tem papel de destaque no ciclo de vida de um produto, as emissões em $\mathrm{CO}_{2}$ são proporcionais a sua fonte de geração (SOCOLOF; OVERLY e GEIBIG, 2005). Com base no exposto e na premissa de que o processo de recondicionamento também utiliza energia, e consequentemente produz emissões de GEE, a primeira proposição analisada neste trabalho é apresentada a seguir:

Proposição 1 - Processos de recondicionamento e a reutilização de recursos de TI impactam negativamente nas emissões de GEE

Segundo Fiering (2006), os serviços relacionados aos computadores nas organizações não têm o seu propósito devidamente avaliado. Serviços como o esforço para busca de fornecedores para a aquisição de novos equipamentos, o tempo de adaptação dos usuários e os projetos de substituição de maquinário tecnológico, demandam tempo e recursos. Portanto, a decisão em proceder com a troca de equipamentos de TI deve observar aspectos de negócio e financeiros, e não apenas tecnológicos.

$\mathrm{O}$ uso de monitores de tela de cristal líquido (LCD), em detrimento aos de tubo de raios catódicos (CRT), teve papel importante no aumento da eficiência energética. Um monitor LCD consome cerca de $30 \%$ da energia de um similar CRT. Entretanto, a sua produção utiliza trifluoreto de nitrogênio $\left(\mathrm{NF}_{3}\right)$ e hexafluoreto de enxofre $\left(\mathrm{SF}_{6}\right)$, e ambos os gases possuem os maiores potenciais de aquecimento global (HOPKINSON e JAMES, 2011). Apesar do aumento da eficiência dos processos ao longo dos anos, a produção de semicondutores exige padrões cada vez mais altos de pureza dos produtos químicos e gases envolvidos, o que, por consequência, intensifica o consumo de energia (WILLIAMS, 2011). Estes aspectos levam à segunda proposição analisada neste trabalho.

Proposição 2 - A substituição de equipamentos de TI por mais atuais e com maior eficiência energética tem impacto positivo em mitigar emissões de GEE.

Xavier e Corrêa (2013) defendem que a vida útil de um produto é definida através da estimativa de tempo em que ele é capaz de manter sua funcionalidade. A produção de equipamentos de TI requer diferentes processos, tais como: a extração de matéria prima, transporte, beneficiamento de semicondutores, encapsulamento dos chips e impressão das placas de circuito eletrônico (CICERI; GUTOWSKY e GARETTI, 2012). Embora a produção de equipamentos de TI demande energia e recursos naturais, contribuindo para o aumento das emissões de GEE, equipamentos mais modernos são mais eficientes em gerar resultados de trabalho utilizando menos energia, promovendo a redução das emissões de GEE durante o uso destes equipamentos (MURUGESAN, 2008; NETO e BLOEMHOF, 2011). Apesar do aumento da eficiência energética ser um importante fator a ser 
considerado na ocasião da substituição de equipamentos obsoletos, Teehan e Kandlikar (2012) destacam que as emissões referentes à fase de uso de tais equipamentos dependem da fonte de geração de energia elétrica do local onde o equipamento é usado. Dessa forma, torna-se necessário também incluir tal fator na averiguação das duas proposições, o que leva a criação da terceira proposição analisada no trabalho.

Proposição 3 - A utilização de energia elétrica a partir de fontes renováveis tem impacto positivo na mitigação de emissões de GEE ao longo de todo o ciclo de vida de equipamentos de TI.

Yao et al. (2010) compararam diversos estudos que tinham por objetivo averiguar qual a fase responsável pelo maior impacto no uso de energia dos equipamentos de TI ao longo do seu ciclo de vida e verificaram uma grande divergência entre eles. A influência da matriz de geração de energia elétrica nas emissões de GEE ainda é pouco explorada pela literatura. Embora não se tenham dados especificamente relacionados à utilização de energia para todo o ciclo de vida de equipamentos de TI, este trabalho busca avaliar o consumo das fases de recondicionamento e uso. Para a fase de uso são consideradas as etapas anteriores e posteriores ao processo de recondicionamento. Cada país apresenta variações em sua matriz energética, contendo um número maior ou menor de fontes não renováveis, o que influi na diferença de emissões entre eles (GOLDEMBERG e LUCON, 2011). Portanto, o trabalho busca esclarecer que discussões sobre o papel de equipamentos de TI no contexto da sustentabilidade ambiental, e mais especificamente do aquecimento global, devem considerar todo o ciclo de vida dos equipamentos. Com isso seria possível um maior entendimento sobre a importância da fonte de geração de energia elétrica, o que poderia ser considerado como um fator de decisão para empresas de TI, bem como um diferencial competitivo para países e locais com essa característica. Segundo relatório da Empresa de Pesquisa Energética (EPE), (2013), para produzir um TWh, no setor elétrico brasileiro emite-se seis vezes menos do que no europeu, sete vezes menos do que no setor elétrico americano e onze vezes menos do que no chinês.

\section{Método}

O trabalho foi desenvolvido como pesquisa exploratória e qualitativa a partir de um estudo de caso único realizado junto ao Polo Marista de Formação Tecnológica do Centro Social Marista (CESMAR). O Polo desenvolve diversos projetos sociais em que o contato dos alunos com o mundo da informática tem por finalidade exercer um papel transformador na sua realidade. Um desses projetos é o do Centro de Recondicionamento de Computadores (CRC), o qual executa a desmontagem e o recondicionamento de equipamentos de informática doados por empresas e comunidade, e os reverte em infraestrutura para o auxílio na inclusão digital e formação técnica profissionalizante de jovens socialmente vulneráveis (XAVIER et al., 2010).

O projeto do Polo Marista está sendo analisado como estudo de caso único neste trabalho, o qual busca gerar uma teoria geral para o conhecimento a partir do entendimento de um fenômeno específico (YIN, 2003). Neste caso, o objetivo é de analisar a relação entre a quantidade de emissões em $\mathrm{CO}_{2}$ eq. mitigado devido ao tempo de uso adicional proporcionado pelo recondicionamento dos computadores e monitores em relação à adoção de equipamentos mais modernos. Embora dados quantitativos dos resultados do consumo de energia e de emissões em $\mathrm{CO}_{2}$ eq tenham sido coletados como parte do trabalho, a pesquisa é considerada exploratória, pois busca analisar percepções e aprimorar ideias a respeito de um fenômeno para o qual se busca um entendimento mais aprofundado e que ainda não é presente na literatura (GIL, 2002). A coleta de dados do trabalho também foi realizada com base em roteiros semiestruturados para direcionar o processo de entrevistas com representantes do Polo Marista de Formação Tecnológica e das entidades beneficiadas. Documentos relativos aos equipamentos recondicionados por esta entidade também foram analisados para confrontar ou reiterar os dados coletados a partir das entrevistas (ROESCH, 2013).

O primeiro instrumento de coleta de dados utilizado foi o roteiro de entrevista 1 (Apêndice A). $\mathrm{O}$ instrumento possibilitou a realização de entrevistas com a coordenadora do Polo Marista de Formação Tecnológica e também com funcionários para coletar dados como: a quantidade e o destino dos equipamentos recondicionados, a idade estimada e quantos anos em média têm sua vida estendida. 
O segundo instrumento utilizado foi o roteiro de entrevista 2 (Apêndice B). O instrumento possibilitou a realização de entrevistas através do telefone com representantes de algumas instituições beneficiadas com os equipamentos doados pelo CESMAR. Dessa forma foi possível coletar dados que permitiram estimar o tempo de uso posterior dos equipamentos, combinando-os com os dados dos pesquisadores referenciados.

As perguntas dispostas nos roteiros de entrevistas 1 e 2 tiveram a finalidade em descobrir dados históricos em relação aos computadores doados, como: a quantidade, a configuração padrão e o destino após o recondicionamento. Outras perguntas dispostas nas entrevistas apuraram o consumo de energia no Polo Marista de Formação Tecnológica e nas entidades beneficiadas para as atividades relacionadas ao recondicionamento, instalação e uso dos equipamentos.

$O$ terceiro instrumento utilizado foi o registro de pesquisa documental através da observação direta (Apêndice C), como não participante da organização. A consulta a documentos disponibilizados posteriormente pela organização (Apêndice D) forneceu informações históricas pertinentes para a execução da análise e permitiu consolidar as informações referentes ao número de equipamentos entregues, a data e o destino. Foram utilizados também dados secundários obtidos através dos trabalhos dos pesquisadores. Com esses dados foi possível identificar o histórico de uso e objetivos de reaproveitamento dos equipamentos recebidos no centro e sobre os processos de reciclagem dos equipamentos.

Através do registro de pesquisa documental, definiu-se cinco categorias entre as entidades contempladas pelo programa. Após a apuração do nome das entidades beneficiadas, contato dos representantes, telefones, data da entrega dos kits e o número de equipamentos por entidade, foi elaborado um gráfico de Pareto e verificou-se que as três categorias beneficiadas pela maior parte das doações são: prefeituras e secretarias, centros sociais e associações e sindicatos. As três categorias detêm um total de $77 \%$ dos computadores entregues. Em seguida, definiu-se uma amostra arbitrada proporcional de seis prefeituras e secretarias, três centros sociais e três associações. Tal critério definiu o número de entrevistas com as instituições beneficiadas.

Como parte do método de pesquisa, o estudo foi restrito a computadores de mesa e monitores dos tipos CRT e LCD em dois cenários distintos. No primeiro, os equipamentos foram recondicionados pelo CESMAR e em seguida doados para reuso em instituições beneficentes. No segundo cenário, assume-se que os equipamentos não são doados ao CRC e, portanto, não tem a segunda fase de uso. Dessa forma, é possível comparar, no mesmo horizonte de tempo, as emissões adicionais que novos equipamentos gerariam ao serem produzidos e utilizados em substituição aos anteriores.

O mesmo horizonte de tempo foi utilizado para os dois cenários, levando em consideração o respectivo fator médio mensal de conversão para inventários corporativos no Brasil, na razão de Toneladas de $\mathrm{CO}_{2}$ equivalentes (tCO2eq.) por Megawatt/hora (MWh). O fator mensal é disponibilizado pelo Ministério da Ciência, Tecnologia e Inovação (MCTI), e até a data da realização da análise, teve o seu último resultado publicado em dezembro de 2013 (MCTI, 2014). Portanto, para a aplicação do método foi necessário adotar um critério para assumir os valores compreendidos no período de janeiro de 2014 a setembro de 2017. Para isso foi calculada a média dos fatores mensais nos três anos anteriores, relativos a cada mês subsequente a dezembro de 2013. Por exemplo, para o mês de janeiro de 2014, calculou-se a média de janeiro nos anos de 2013, 2012 e 2011.

As emissões referentes à fase de produção dos equipamentos correspondem as da extração dos materiais e fabricação do produto final. As emissões na fase de uso foram estimadas a partir dos dados obtidos de representantes do CRC e instituições beneficiadas, e calculadas com o uso da ferramenta online eXtreme Power Supply Calculator Lite (EPSC,2013). A ferramenta possibilita que técnicos de informática, profissionais de TI e entusiastas possam estimar a potência mínima necessária para a fonte de energia a ser instalada em um computador, a partir das peças que o compõem. A potência dos monitores do tipo CRT e LCD foi aferida diretamente a partir da observação das informações de fábrica que constavam em equipamentos presentes no CRC. Para a realização do trabalho, partiu-se da premissa que os equipamentos, tanto na fase anterior ao CRC quanto posterior, operam em modo normal. No caso deste trabalho isto se refere à utilização de aplicativos que demandam menor consumo para a utilização do equipamento. Como exemplo, um navegador de web, uma planilha eletrônica (Excel) ou um editor de texto (Word). 
As emissões referentes à fase de recondicionamento foram estimadas com base nas entrevistas com representantes do CRC. O trabalho consome diretamente uma quantidade de energia elétrica para o recondicionamento, instalação e testes dos equipamentos. O consumo nessas três fases é diretamente proporcional ao número de computadores, e ao respectivo mês e ano de uso. Foi estimada ainda a energia utilizada pelas lâmpadas presentes no galpão e também a de um ventilador industrial. Nesse caso, verificou-se também a influência de fatores climáticos relativos à época do ano, clima e temperatura. Detalhes sobre os dados e resultados analisados a partir das observações estão apresentados na seção a seguir e servem de apoio para confirmar a Proposição 3 deste trabalho.

\section{Análise e Discussão dos Resultados}

A coleta de dados no Polo Marista de Formação Tecnológica foi realizada nos meses de setembro e outubro de 2013 e envolveu pessoal da coordenação e do corpo técnico de reciclagem dos equipamentos de TI. Todas as entrevistas foram gravadas eletronicamente e as principais observações foram transcritas para revisão junto aos entrevistados e tabulação para análise de resultados.

De acordo com a coordenação do CESMAR, os equipamentos recebidos são doados em conjuntos de monitores e computadores. Quanto aos monitores, o corpo técnico indicou que os modelos CRT ainda representam a maioria das doações, os quais não são recondicionados, mas apenas reutilizados. Os computadores recebidos são recondicionados e colocados à disposição para retirada pelas entidades que os recebem. Os equipamentos são disponibilizados em conjuntos padronizados que compreendem um total de onze computadores e monitores.

De acordo com o corpo técnico do CESMAR, existem padrões e critérios para a configuração dos computadores recondicionados no CRC. A justificativa para isso se deve ao fato de que alguns componentes e periféricos possuem incompatibilidade entre si, com o software livre utilizado nos equipamentos a serem doados. No que diz respeito à configuração básica dos computadores, os processadores usualmente são da geração Pentium IV, ou sua versão mais econômica, o Celeron. A maior parte dos processadores doados são modelos que operam nas velocidades de $2.8 \mathrm{GHz}$ a $3.2 \mathrm{GHz}$. Os demais componentes mais comumente utilizados são: placas de memória com 256MB de RAM, discos de armazenamento de 40GB a 80GB e leitores de CD e DVD.

As atividades de recondicionamento são executadas de segunda a sexta-feira, durante oito horas diárias, em uma área tipo galpão, que utiliza 16 lâmpadas com potência de 400 watts. No local estão instalados também dois ventiladores industriais com potência de $1,5 \mathrm{CV}$, o que equivale a aproximadamente $1,1 \mathrm{~kW}$. Com base na observação direta foi percebido que as 16 lâmpadas e apenas um ventilador estavam diretamente relacionados ao local onde ocorre o trabalho do CRC. As lâmpadas são utilizadas durante grande parte do dia, em adição a iluminação direta do ambiente externo, garantindo a homogeneidade da luminosidade no ambiente de trabalho, mesmo em dias de sol. Segundo os técnicos que trabalham no local, a variação de temperatura e luminosidade no local determina o tempo de uso das lâmpadas e ventiladores durante o ano. $\mathrm{O}$ tempo necessário para o recondicionamento e instalação de software é de aproximadamente quatro horas. Após essa etapa é necessário também manter o equipamento em funcionamento durante um dia para realizar testes de estresse.

Durante a pesquisa foi identificado que o Ministério Público do Rio Grande do Sul (MPRS) detém dados referentes aos detalhes técnicos dos equipamentos doados. Portanto, este foi contatado e forneceu a lista de doações dos anos de 2010, 2012 e 2013. Dados de anos anteriores e do ano de 2011 não foram contabilizados pelo MPRS. No trabalho foi aferido um total de 534 conjuntos de 11 computadores e monitores. Os dados coletados nas entrevistas e de documentos foram tabulados em planilha eletrônica (Excel) e indicam que são cinco as categorias de entidades mais contempladas pelo programa. Para cada conjunto foram coletados dados de uso e configuração. As principais entidades beneficiadas pelas doações foram: (i) prefeituras e secretarias públicas, (ii) centros sociais e (iii) associações e sindicatos. Estas categorias de entidades representam um total de $77 \%$ dos computadores entregues e foram contatadas para a coleta de dados de uso dos equipamentos. O contato foi efetuado com seis prefeituras e secretarias, três centros sociais e três associações, permitindo uma amostragem que representa 77\% das doações. A Tabela 1 apresenta a distribuição de equipamentos (computadores e monitores) por entidades, assim como a porcentagem acumulada de doações no período analisado. 
Tabela 1- Distribuição de equipamentos por entidades

\begin{tabular}{c|c|c|c|c|}
\hline Entidades & $\mathbf{N}^{\text {o de entidades }}$ & $\begin{array}{c}\mathbf{N}^{\circ} \text { de Conjuntos } \\
\text { de equipamentos }\end{array}$ & Acumulado & \% Acumulado \\
\hline Prefeituras e secretarias & 22 & 221 & 221 & 41,4 \\
Centros sociais & 11 & 101 & 322 & 60,3 \\
\hline Associações e sindicatos & 11 & 89 & 411 & 77,0 \\
Obras assistenciais & 5 & 65 & 476 & 89,1 \\
Escolas & 6 & 58 & 534 & 100,0 \\
\hline
\end{tabular}

Fonte: Os Autores (2014)

As entrevistas e coleta de dados com as instituições foram inicialmente agendadas por telefone e formalizadas por correio eletrônico. Grande parte dos dados coletados foi enviada por e-mail, mas também foram realizadas entrevistas presenciais, nas quais se identificou que a maioria dos computadores foram destinados a tele centros e bibliotecas virtuais. Por exemplo, o representante da Prefeitura de Cerro Branco relatou que "Os computadores recebidos estão instalados e funcionando plenamente na biblioteca da cidade para uso de alunos e da população em geral. Os mesmos ficam à disposição durante oito horas diárias, no horário de expediente da Biblioteca, de segunda a sextafeira". O representante da Prefeitura de Restinga Seca informou que "Os equipamentos doados estão disponíveis para uso dos projetos da Assistência Social e para uso da comunidade por oito horas diárias, de segunda a sexta-feira. Até o momento não houve descarte de nenhum equipamento". A grande maioria dos representantes das entidades beneficiadas informaram que os equipamentos recebidos estavam em plena operação, e a maior parte da manutenção necessária se restringia à configuração de software, o que indica sobre a vida útil dos equipamentos originais. Em relação ao tempo de operação dos equipamentos, houve pouca variação em relação ao período de oito horas de uso diário em cinco dias da semana. Situação similar de uso e manutenção foi indicada pelo corpo técnico do CESMAR, o qual também possui um tele centro localizado no mesmo bairro da entidade, em funcionamento desde 2006. Segundo os técnicos, os equipamentos atendem à comunidade necessitando apenas de manutenção esporádica, geralmente relacionado ao uso indevido do software instalado nos equipamentos.

\subsection{Recondicionamento e Operação dos Equipamentos nas Duas Fases de Uso}

O processo de recondicionamento tem início no CESMAR logo após o recebimento dos equipamentos doados. Na sequência é realizado um processo de triagem, no qual os equipamentos são avaliados, separados e armazenados para o recondicionamento. Após serem recondicionados, os equipamentos são entregues para uso nas instituições beneficiárias, sendo que todo o processo leva em torno de 50 dias. Para a realização das estimativas do trabalho, convencionou-se que os equipamentos recondicionados são colocados à disposição das instituições beneficiadas após dois meses do recebimento pelo CRC (60 dias). Não foram fornecidos dados relativos ao ano de 2011, portanto foi necessário abranger um horizonte de tempo de doze anos. Assim foi possível contemplar as fases de uso anterior e posterior ao trabalho do CRC de todos os equipamentos apurados, desde o primeiro em 2010, até o último em 2013. A Tabela 2 apresenta a quantidade de equipamentos em operação no período do estudo.

Tabela 2 - Quantidade de computadores em operação nas três fases analisadas

\begin{tabular}{c|c|c|c|c|c|c|c|c|c|c|c|c}
\hline Anos 2006-2017 & $\mathbf{0 6}$ & $\mathbf{0 7}$ & $\mathbf{0 8}$ & $\mathbf{0 9}$ & $\mathbf{1 0}$ & $\mathbf{1 1}$ & $\mathbf{1 2}$ & $\mathbf{1 3}$ & $\mathbf{1 4}$ & $\mathbf{1 5}$ & $\mathbf{1 6}$ & $\mathbf{1 7}$ \\
\hline $\mathbf{1}^{\mathbf{a}}$ Fase de uso & 214 & 214 & 484 & 534 & 320 & 320 & 50 & 0 & 0 & 0 & 0 & 0 \\
Recondicionamento & 0 & 0 & 0 & 0 & 214 & 0 & 270 & 50 & 0 & 0 & 0 & 0 \\
$\mathbf{2}^{\mathbf{a}}$ Fase de uso & 0 & 0 & 0 & 0 & 214 & 214 & 484 & 534 & 320 & 320 & 50 & 0 \\
\hline
\end{tabular}

Fonte: Os Autores (2014) 
O tempo mensal de operação dos equipamentos na primeira fase foi definido após a análise do conteúdo das entrevistas com representantes do CRC. A maior parte das doações é proveniente de organizações públicas e privadas, e também de apreensões a partir de atividades policiais. Considerouse que durante a primeira fase de uso os equipamentos funcionavam durante nove horas e meia. Esse período corresponde ao horário comercial e a um período adicional de uma hora e meia, o qual poderia também contemplar o uso em horas extras e no intervalo de refeições de funcionários.

$\mathrm{Na}$ segunda fase, o tempo mensal foi definido pela finalidade do uso nas instituições beneficiadas. Nas entrevistas foi apurado que o período de utilização médio dos equipamentos é de oito horas diárias, durante cinco dias por semana. Para anular o impacto da diferença no tempo de uso diário em cada fase, e da variação da matriz energética ao longo dos anos, foram estimadas também as emissões a partir de duas situações hipotéticas. Na primeira assumiu-se que os equipamentos funcionaram por oito horas diárias em ambas as fases. Na segunda, além do mesmo número de horas, assumiu-se que a matriz energética também não variou. Dessa forma, considerou-se que na segunda fase de uso, em ambos os cenários propostos, o fator médio mensal permaneceu igual ao dos 48 meses da primeira fase.

A estimativa dos anos de uso da primeira fase foi feita a partir da análise do roteiro de entrevista com os representantes do CRC e também por informações da revisão de literatura. O tempo médio da primeira fase de uso de um computador no Brasil varia entre três e quatro anos (CARVALHO, 2008). O tempo de uso na segunda fase foi estimado a partir da análise do roteiro de entrevista com os representantes das entidades e também com dados de pesquisadores referenciados.

\subsection{Estimativa de Emissões em $\mathrm{CO}_{2}$ eq. Mitigado pelo trabalho do $\mathrm{CRC}(2010,2012$ e 2013)}

Para a fase de produção dos monitores CRT e LCD foram considerados os resultados obtidos por Socolof, Overly e Geibig (2005). A escolha se justifica, pois o trabalho citado teve como escopo apenas estes dois tipos de monitores e oferece resultados sobre as emissões resultantes dos processos e componentes químicos utilizados na fabricação de ambos. Para a fase de produção de um computador com as características próximas aos dos recondicionados pelo CRC foi considerado o resultado indicado por Teehan e Kandlilkar (2013). Um aspecto considerado positivo foi o fato de que este resultado é referente a um computador similar aos recondicionados pelo CRC, e considera um PC típico do ano de 2002, o qual representa a primeira geração de processadores Pentium IV, com a velocidade similar aos recondicionados pelo CRC (INTEL, 2013). Na Tabela 3 estão dispostos os dados técnicos relativos aos equipamentos analisados, conforme apurado nas entrevistas e coletados no CESMAR. As especificações técnicas da Configuração 1 correspondem as dos equipamentos recondicionados pelo CRC. Para a Configuração 2 foram definidas configurações técnicas que representam um equipamento (computador e monitor) padrão adquirido no ano de 2010, a qual é similar aos equipamentos analisados por Teehan e Kandlikar (2013) e Socolof, Overly e Geibig (2005). Complementam a tabela, os dados relativos à potência estimada dos equipamentos assim como as emissões em $\mathrm{CO}_{2}$ eq. decorrentes da produção.

Tabela 3 - Dados técnicos dos equipamentos analisados e estimativas de emissões para produção

\begin{tabular}{|c|c|c|c|}
\hline & $\begin{array}{c}\text { Configuração 1 } \\
\text { (Recondicionados) }\end{array}$ & $\begin{array}{c}\text { Configuração } 2 \\
\text { (2010) }\end{array}$ & Referências \\
\hline $\begin{array}{l}\text { Especificações } \\
\text { Técnicas }\end{array}$ & $\begin{array}{l}\text { Processador Pentium IV ou } \\
\text { Celeron; 2.8GHz/ 3.2GHz; } \\
\text { Memória RAM 256MB; HD } \\
\text { 40/80GB Monitor CRT }\end{array}$ & $\begin{array}{l}\text { Processador Intel Core } 2 \\
\text { Duo 2.67GHz; Memória } \\
\text { RAM 2GB; HD 250GB; } \\
\text { Monitor LCD }\end{array}$ & CESMAR \\
\hline Potência & $234 \mathrm{~W}$ & $195,3 \mathrm{~W}$ & (EPSC, 2013) \\
\hline \multirow{2}{*}{$\begin{array}{l}\text { Emissão em } \\
\mathrm{CO}_{2} \text { eq. para } \\
\text { Produção }\end{array}$} & $322 \mathrm{kgCO}_{2}$ eq. $(\mathrm{CPU})$ & $161 \mathrm{kgCO}_{2}$ eq. $(\mathrm{CPU})$ & $\begin{array}{l}\text { (TEEHAN e } \\
\text { KANDLIKAR, } \\
2013 \text { ) }\end{array}$ \\
\hline & $235 \mathrm{kgCO}_{2}$ eq. (MONITOR) & $422 \mathrm{kgCO}_{2}$ eq. (MONITOR) & $\begin{array}{l}\text { (SOCOLOF, } \\
\text { OVERLY e } \\
\text { GEIBIG, 2005) }\end{array}$ \\
\hline
\end{tabular}


A Tabela 4 apresenta o tempo mensal de uso dos equipamentos analisados, contemplando o resultado apurado a partir das entrevistas com os representantes do CRC-CESMAR e das instituições beneficentes. Foi apresentado também o resultado que tem por finalidade averiguar a situação hipotética em que o tempo de uso mensal não sofreria variação nas diferentes fases.

Tabela 4 - Tempo de uso mensal dos equipamentos analisados

\begin{tabular}{l|c|c|c|c}
\hline \multicolumn{1}{c|}{ Uso Mensal } & \multicolumn{2}{c|}{ Configuração 1 } & \multicolumn{2}{c}{ Configuração 2 } \\
\hline $\begin{array}{l}\text { Variação de } \\
\text { horas de uso }\end{array}$ & $\begin{array}{c}\text { Com variação } \\
\text { (horas) }\end{array}$ & $\begin{array}{c}\text { Sem variação } \\
\text { (horas) }\end{array}$ & $\begin{array}{c}\text { Com variação } \\
\text { (horas) }\end{array}$ & $\begin{array}{c}\text { Sem variação } \\
\text { (horas) }\end{array}$ \\
\hline $\mathbf{1}^{\mathbf{a}}$ fase & 190 & 160 & - & - \\
\hline $\mathbf{2}^{\mathbf{a}}$ fase & 160 & 160 & 160 & 160 \\
\hline
\end{tabular}

Fonte: Os Autores (2014)

A Tabela 5 apresenta o resultado das emissões em $\mathrm{CO}_{2}$ eq. nas duas fases de uso dos equipamentos analisados e também devido ao trabalho de recondicionamento dos computadores no CRC. A Tabela apresenta também um resultado que representa a situação hipotética em que não ocorreria variação nas horas de uso dos equipamentos e das emissões em $\mathrm{CO}_{2}$ eq decorrentes da matriz energética em ambas as fases.

Tabela 5 - Emissão em $\mathrm{CO}_{2}$ eq dos equipamentos analisados devido ao uso e ao recondicionamento

\begin{tabular}{|c|c|c|c|c|}
\hline Emissão em $\mathrm{CO}_{2}$ eq. & \multicolumn{2}{|c|}{ Configuração 1} & \multicolumn{2}{|c|}{ Configuração 2} \\
\hline $\begin{array}{l}\text { Variação de horas de } \\
\text { uso e emissões }\end{array}$ & $\begin{array}{l}\text { Com variação } \\
\left(\text { tCOO }_{2} \text { eq. }\right)\end{array}$ & $\begin{array}{c}\text { Sem variação } \\
\left(\mathrm{tCO}_{2} \mathrm{eq} .\right)\end{array}$ & $\begin{array}{l}\text { Com variação } \\
\left(\mathrm{tCO}_{2} \mathrm{eq} .\right)\end{array}$ & $\begin{array}{c}\text { Sem variaçãa } \\
\left(\mathrm{tCO}_{2} \mathrm{eq} .\right)\end{array}$ \\
\hline $1^{\mathrm{a}}$ fase de Uso & 42,01 & 35,38 & - & - \\
\hline $2^{\text {a fase de Uso }}$ & 70,23 & 35,38 & 58,62 & 29,53 \\
\hline Recondicionamento & \multicolumn{2}{|c|}{0,82} & \multicolumn{2}{|c|}{-} \\
\hline
\end{tabular}

Fonte: Os Autores (2014)

Tendo em vista a discordância entre qual das fases é responsável pela maior quantidade de emissões de GEE (Cicery, Gutowsky e Garetti, 2012; Deng, Babbit e Williams, 2011; Pickavet et al., 2008; Socolof, Overly e Geibig, 2005; Teehan e Kandlikar, 2013; Williams, 2011; Yao et al., 2010), ambas as fases foram consideradas na elaboração das fórmula, juntamente com a fase de remanufatura no Polo Marista. A diferença entre a quantidade de emissões em $\mathrm{CO}_{2}$ eq. mitigado pelo trabalho do CRC foi estimada a partir dos dois cenários propostos no método de pesquisa do trabalho. No primeiro foi estimada a quantidade, em $\mathrm{CO}_{2}$ eq., emitida pelos 534 conjuntos de computadores e monitores nas fases de produção, recondicionamento e de uso anterior e posterior ao CRC. Em seguida o total foi dividido pelo número de anos referentes à primeira e à segunda fase de uso. A estimativa foi efetuada com base na seguinte fórmula:

$$
\operatorname{kgCO} 2 e q .1 / a . a=\frac{\alpha E p 1+E r+\sum_{1}^{8} E u n}{8}
$$

Onde:

$\mathrm{kgCO}_{2}$ eq.1 = quantidade de emissões em $\mathrm{CO}_{2}$ eq. ao ano para equipamentos reaproveitados $\alpha=$ quantidade de conjuntos de computadores e monitores apurados

Ep1 = quantidade de emissões em $\mathrm{CO}_{2}$ eq. para a manufatura de um conjunto de equipamentos

$\mathrm{Eu}=$ quantidade anual de emissões em $\mathrm{CO}_{2}$ eq. nas fases de uso anteriores e posteriores ao CRC

$\mathrm{n}=$ anos das fases de uso dos equipamentos, sendo que $\mathrm{n} 1 \rightarrow 8$

No segundo cenário foi estimada a quantidade de $\mathrm{CO}_{2}$ eq. emitida no mesmo horizonte temporal relativo a dois conjuntos de equipamentos distintos. $\mathrm{O}$ primeiro conjunto corresponde ao mesmo tipo dos computadores e monitores CRT recondicionados. O segundo corresponde a um 
computador de configuração equivalente a um similar do ano de 2010 com monitor LCD. A escolha se justifica pelo fato de que coincide com o ano em que foi apurado o primeiro conjunto de computadores e monitores recondicionados pelo CRC, e também pelo fato de que, nessa época, o preço de um monitor LCD já se apresentava como vantajoso para o consumidor final em relação aos de CRT. Dessa forma foi possível averiguar as três proposições e estimar sobre a extensão do uso dos computadores e monitores recondicionados em contraposição à demanda por equipamentos mais recentes, se teriam impacto positivo ou negativo quanto às emissões em $\mathrm{CO}_{2}$ eq. A fórmula utilizada para a estimativa das emissões em $\mathrm{CO}_{2}$ eq. nesse cenário é:

$$
\text { kgCO2eq. } 2 / a \cdot a=\frac{\alpha E p 1+\sum_{1}^{4} E u n}{4}+\frac{\beta E p 2+\sum_{1}^{4} E u m}{4}
$$

Onde:

$\mathrm{kgCO}_{2}$ eq.2 = quantidade em $\mathrm{CO}_{2}$ eq. emitida ao ano para equipamentos não reaproveitados $\alpha=$ quantidade de conjuntos de computadores e monitores produzidos até 2010 (configuração 1) $\beta=$ quantidade de conjuntos de computadores e monitores produzidos após 2010 (configuração 2) Ep1 = quantidade de emissões em $\mathrm{CO}_{2}$ eq. para a manufatura de um conjunto da configuração 1 $\mathrm{Ep} 2$ = quantidade de emissões em $\mathrm{CO}_{2}$ eq. para a manufatura de um conjunto da configuração 2 $\mathrm{Eu}=$ quantidade anual de emissões em $\mathrm{CO}_{2}$ eq. nas fases de uso dos equipamentos. $\mathrm{n}=$ anos da fase de uso do primeiro aparelho, sendo que $\mathrm{n} 1 \rightarrow 4$ $\mathrm{m}=$ anos da fase de uso do segundo aparelho, sendo que $\mathrm{m} 1 \rightarrow 4$ $\alpha=\beta$

Após a estimativa da quantidade de emissões em $\mathrm{CO}_{2}$ eq. por ano nos dois cenários distintos, foi calculada a diferença entre eles. Foi considerado o horizonte temporal das duas fases de uso. Dessa forma, o resultado obtido foi multiplicado pelos oito anos correspondentes. A fórmula utilizada foi a seguinte:

\section{$t C 02 e q .=t C 02 e q .2-t C 02 e q .1$}

A Tabela 6 apresenta os resultados obtidos da diferença em $\mathrm{tCO}_{2} \mathrm{eq}$ emitido entre os dois cenários. Apresenta também a diferença ao considerar as duas outras situações hipotéticas propostas em que não ocorreria a variação de horas de uso nem de emissões em $\mathrm{CO}_{2}$ eq decorrentes da matriz energética em ambas as fases. Ao igualar o número de horas de uso em ambas as fases, obteve-se o resultado de 1001,64 tCO2eq., com uma variação negativa de 0,66\%. Considerando o mesmo número de horas de uso e fator de emissões mensais nas duas fases, obteve-se o resultado de 985,73 tCO2eq., com uma variação negativa de $2,97 \%$. Em um tempo de uso total de oito anos, referentes às fases anterior e posterior ao recondicionamento e considerando-se que o uso de cada conjunto utiliza energia elétrica baseado em resultados do SIN, estimou-se um consumo total de 210,19 kgCO2eq. Portanto, verifica-se que um conjunto de equipamentos levaria 21 anos em funcionamento para igualar as emissões da sua produção. Conclui-se que, conforme os cenários propostos no estudo de caso, a fase de produção responde por $72,6 \%$ do total das emissões. Em complemento ao resultado total, foram dispostos na Tabela 6 o resultado em $\mathrm{CO}_{2}$ eq. mitigado anualmente e também por cada equipamento recondicionado.

Tabela 6 - Resultados finais de emissões mitigadas em $\mathrm{CO}_{2} \mathrm{eq}$.

\begin{tabular}{|c|c|c|c|}
\hline Emissão em CO2eq. & $\begin{array}{l}\text { Valor Referencial } \\
\quad\left(\mathrm{tCO}_{2} \text { eq. }\right)\end{array}$ & $\begin{array}{l}\text { Sem variação de horas } \\
\text { de uso }\left(\mathrm{tCO}_{2} \text { eq. }\right)\end{array}$ & $\begin{array}{l}\text { Sem variação de horas de uso e } \\
\text { de emissões ( }\left(\mathrm{tCO}_{2} \text { eq. }\right)\end{array}$ \\
\hline Total & 1008,27 & 1001,64 & 978,32 \\
\hline Por Ano & 126,03 & 125.20 & 122,29 \\
\hline $\begin{array}{l}\text { Por Equipamento } \\
\text { (CPU e monitor) }\end{array}$ & 1,89 & 1,87 & 1,83 \\
\hline
\end{tabular}


Na comparação no mesmo período de tempo (os quatro anos referentes à segunda fase de uso), os equipamentos recondicionados são responsáveis por uma maior quantidade de emissões, totalizando $70,23 \mathrm{tCO}_{2}$ eq. Por outro lado, os equipamentos mais novos respondem por um total de 58,62 $\mathrm{tCO}_{2} \mathrm{eq}$. Estes resultados dão suporte de forma parcial à Proposição 2, demonstrando que a aquisição de equipamentos mais eficientes contribui positivamente para a mitigação de emissões em $\mathrm{CO}_{2}$ eq., mas apenas na fase de uso. No entanto, o baixo consumo de energia no processo de recondicionamento e a pequena diferença no consumo de energia entre produtos novos e reutilizados não supera as emissões da fase de produção. Portanto, a reutilização pode ser considerada uma prática que contribui para a mitigação de emissões de GEE se considerada a totalidade do ciclo de vida dos equipamentos de TI, o que refuta a Proposição 1

Após a análise das três fases (produção, recondicionamento e uso) verificou-se que a diferença no total de emissões, ao comparar equipamentos recondicionados e novos, é de $1008 \mathrm{tCO}_{2}$ eq. Isto torna a reutilização, do ponto de vista da sustentabilidade, uma opção bastante efetiva. Os resultados indicam que, para estimar as emissões relativas ao uso de equipamentos de TI, devem ser considerados quatro fatores: (i) as emissões para a produção, (ii) para recondicionamento, (ii) para o uso e (iv) também as relativas à fonte de geração elétrica do local onde o produto é utilizado. Considerando a prevalência da matriz renovável de geração de energia elétrica no Brasil (PORTAL BRASIL, 2013), e que a fase de produção dos equipamentos analisados no estudo é responsável por 72,6\% das emissões totais, verifica-se que as emissões na fase de uso dos equipamentos dependem de forma significativa da fonte de geração de energia elétrica do local onde o equipamento é usado (TEEHAN e KANDLIKAR, 2012), o que confirma a importância em desenvolver trabalhos que analisem especificamente a utilização de energia e recursos necessários na fase de produção. Os atuais resultados do trabalho confirmam a Proposição 3 para as fases de uso e de recondicionamento de equipamentos de TI.

\section{Conclusões}

As conclusões do trabalho estão relacionadas diretamente com os objetivos e proposições avaliadas na pesquisa. Das três proposições testadas, apenas uma delas foi suportada integralmente pelos resultados. O recondicionamento de 534 conjuntos de equipamentos (computadores e monitores), cujos dados são referentes aos anos de 2010, 2012 e 2013, proporcionou a mitigação de $1008 \mathrm{tCO}_{2}$ eq. em um período de oito anos, o que corresponde a 1008 créditos de carbono. Portanto, os resultados encontrados indicam que a reutilização de equipamentos de TI tem impacto positivo na mitigação de emissões GEE. Por outro lado, a Proposição 2 comprova que a aquisição de equipamentos mais eficientes contribui positivamente para a mitigação de emissões, mas apenas na fase de uso. Considerando as emissões totais das fases de produção, uso e recondicionamento, a aquisição de novos equipamentos seria responsável por uma quantidade superior de emissões em relação à reutilização dos equipamentos recondicionados.

O objetivo geral de analisar o quanto a reutilização de equipamentos de TI contribui para a mitigação de emissões de GEE foi atingido. Os resultados estão em consonância com os resultados de Hopkinson e James (2011), Williams (2004) e Murugesan (2008), os quais indicam que o recondicionamento e a reutilização são recomendáveis sob um ponto de vista sustentável. No contexto recente, futuros trabalhos são sugeridos para estimar a intensidade energética e as emissões correspondentes decorrentes da produção de equipamentos atuais com características e funções similares aos analisados no presente estudo. Faz-se mister verificar o quanto a evolução tecnológica dos equipamentos de TI, o aumento da eficiência e a racionalização do consumo de recursos no processo produtivo, contribuem para mitigar as emissões de GEE na fase de produção.

A quantidade de emissões mitigadas em $\mathrm{CO}_{2}$ eq., corresponde a de 332 carros do modelo Chevrolet Cruze, ou 354 do modelo Fiat Bravo Dual Logic, ou 387 do modelo Honda Civic, considerando os modelos com motor 1.8 e rodando $15000 \mathrm{~km}$ por ano (ANFAVEA, 2014). Portanto, a reutilização de equipamentos de TI é uma prática que contribui para a mitigação de emissões de GEE.

O Polo Marista não pleiteou a qualificação do recondicionamento de computadores como um projeto de MDL. Portanto, este não se beneficia da venda de Reduções Certificadas de Emissões 
(RCE). Perera, Kerr e Kimura (2010) destacam que o Brasil possui grande potencial para que projetos de MDL sejam desenvolvidos. No âmbito nacional, a certificação de um projeto de MDL depende de critérios rígidos e da análise de órgãos credenciados pelo governo brasileiro e pela ONU. O presente estudo não teve no escopo o propósito de analisar estes itens, os quais devem atender a três critérios (HEPBURN, 2007): (i) devem ser reais, (ii) devem ser mensuráveis, e (iii) a redução das emissões deve ser adicional àquelas que ocorreriam na ausência do projeto.

$\mathrm{O}$ estudo teve limitações referentes à impossibilidade em obter-se dados precisos sobre a origem e tempo do uso pregresso dos equipamentos, o que se deve ao fato de não haver registros dos tipos de peças recebidas e posteriormente utilizadas nos equipamentos recondicionados. Na situação em que as horas de uso permaneceram iguais nas duas fases, obteve-se uma variação negativa de $0,66 \%$. Mantendo-se o fator médio mensal e as horas de uso iguais, obteve-se uma variação negativa de $2,97 \%$. Os resultados obtidos no estudo demonstram também que o fato da matriz de geração de energia elétrica brasileira ser composta em sua maioria por fontes renováveis, contribui para tornar a reutilização de equipamentos uma opção ainda mais positiva no auxílio da mitigação de GEE. A preponderância das emissões na fase de produção, confirma a Proposição 3 para as fases de uso e de recondicionamento dos equipamentos

A principal contribuição do artigo para a instituição CESMAR foi demonstrar que o CRC promove benefícios ambientais mensuráveis. De forma mais ampla, demonstrou-se que o benefício gerado pelo CRC contribui para a mitigação de GEE. Na medida em que a responsabilidade socioambiental e o mercado de créditos de carbono adquirem maior relevo no cenário mundial, organizações como o CRC podem ter a sua importância ampliada na busca de um mundo mais sustentável. Atualmente, o CRC recebe uma grande quantidade de equipamentos que não são aproveitáveis, entretanto, podem ser vendidos como sucata eletrônica para empresas de reciclagem. A mensuração do possível retorno financeiro para o Polo Marista, e os respectivos benefícios ambientais proporcionados, pode representar um importante fator para ampliar a divulgação de suas atividades para a sociedade e atrair investimentos. No entanto, futuros estudos serão necessários para aferir tais possibilidades.

\section{Referências}

ANFAVEA (Associação Nacional dos Fabricantes de Veículos Automotores). Emissões. Disponível em: <http://www.anfavea.com.br/emissoes.html >. Acesso em: 12 mar. 2014.

BAUMANN, H.; TILLMAN, A. The Hitch Hiker's Guide to LCA: An orientation in life cycle assessment methodology and application. Lund, Sweden: Studentliteratur, 2004, 544 p.

BMFBOVESPA. Mercado de Carbono. Disponível em: <http://www.bmfbovespa.com.br/ptbr/noticias/2010/BMFBOVESPA-realiza-leilao-de-creditos-de-carbono-voltado-ao-mercadovoluntario-2010-04-07.aspx?tipoNoticia=1\&idioma=pt-br>. Acesso em: 23 mai. 2013.

BOCCALETTI, G.; LÖFFLER, M.; OPPENHEIM, J. M. 2008. How IT can cut carbon emissions. The Mckinsey Quarterly. Disponível em: 〈http://www.kyotoclub.org/docs/mckinsey it ott08.pdf>. Acesso em: 23. mai. 2013.

CARVALHO, T. C. M. B. CEDIR - Centro de Descarte e Reuso de Resíduos de Informática. In: V Fórum da Agenda Ambiental na Administração Pública (A3P). São Paulo, SP, Brasil. 2008. Disponível em:

<http://www.mma.gov.br/estruturas/a3p/_arquivos/6_cedir_ttereza_carvalho_36.pdf >. Acesso em: 20 set. 2013.

CHEN, C.; GÜTSCHOW, J.; VIEWEG, M.; MACEY, K.; SCHAEFFER, M. Impact of the Doha outcome on surplus emission allowances and their effect on developed country emissions. Climatic Change. v. 120, n. 4, p. 845-857, out. 2013. 
CICERI, N. D.; GUTOWSKI, T. G.; GARETTI, M. A Tool to Estimate Materials and

Manufacturing Energy for a Product. In: International Symposium on Sustainable Systems and Technology, 2010. Arlington, VA, USA. New Jersey, USA: IEEE, 2010.

DENG, L.; BABBIT, C. W., WILLIAMS, E. D. Economic-balance hybrid LCA extended with uncertainty analysis: case study of a laptop computer. Journal of Cleaner Production. v. 19, n. 11, p. 1198-06, 2011.

ECOINVENT (Ecoinvent Centre). The Ecoinvent Database. Disponível em: <http://www.ecoinvent.org/database>. Acesso em: 08 jun. 2013.

EPE (Empresa de Pesquisa Energética). Balanço Energético Nacional 2013. Disponível em: < https://ben.epe.gov.br/downloads/S\%C3\%ADntese\%20do\%20Relat\%C3\%B3rio\%20Final_2013_Web .pdf>. Acesso em: 10 nov. 2013.

EPSC. Extreme Power Supply Calculator Lite. Disponível em: < http://www.extreme.outervision.com/psucalculatorlite.jsp>. Acesso em: 15 nov. 2013.

FIERING, L. Best Practices in PC Life Cycle Services. Disponível em: < https://www.gartner.com/doc/490086/best-practices-pc-life-cycle>. Acesso em: 16 mai. 2013.

FUJII, K.; YAMAGIWA, M.; UEHARA, M. A Study on Improving the System of Grid Powered by Solar Cell. In: 14th International Conference on Network-Based Information Systems (NBiS-2011). Tirana, Albania. IEEE, 2011. p. 535-540.

GIL, A. C. Como elaborar projetos de pesquisa. 4. ed. São Paulo: Atlas. 2002, 200 p.

GOLDEMBERG, J.; LUCON, O.. Energia, Meio ambiente e Desenvolvimento. 3. ed. São Paulo: Edusp, 2011, 394 p.

GUILTINAN, J. Creative Destruction and Destructive Creations: Environmental Ethics and Planned Obsolescence. Journal of Business Ethics. v.89, n.1, p.19-28, Mai. 2009.

HEPBURN, C. Carbon Trading: A Review of The Kyoto Mechanisms. Annual Review of Environment and Resources. v. 32, p. 375-393. 2007.

HOPKINSON, L.; JAMES, P. Life Cycle Energy and Environmental Impacts of Computing Equipment - A June 2011 Update to a 2009 SusteIT Report. Disponível em:

$<$ http://www.goodcampus.org/files/files/57-

LCA_of_computing_equipment_v7_final_June_2011.pdf>. Acesso em: 23 mai. 2013.

INTEL. Microprocessor Quick Reference Guide. Disponível em:

<http://www.intel.com/pressroom/kits/quickrefyr.htm>. Acesso em: 19 out. 2013.

HEINRICH, A. B.; KLÖPFFER, W. Integrating a new section in Int J LCA. The International Journal of Life Cycle Assessment, v. 7, n. 6, p. 315-316, 2002.

LOOS, P.; NEBEL, W.; GÓMEZ, J. M.; HASAN, H.; WATSON, R. T.; VOM BROCKE, J.; SEIDEL, S.; RECKER, J.. Green IT: A Matter of Business and Information Systems Engineering? Business \& Information Systems Engineering. v. 3, n.4, p.245-252, ago. 2011.

MAGA, D.; HIEBEL, M.; KNERMANN, C. Comparison of two ICT solutions: desktop PC versus thin client computing. The International Journal of Life Cycle Assessment. v. 18, n. 4, p. 861-871, mai. 2013. 
MARQUES, F.; MAGALHÃES, G.; PARENTE, V.; ROMEIRO, V. Regulação Tributária do Mercado de Carbono no Brasil: Entraves e Perspectivas. In:VII Congresso Brasileiro de Planejamento Energético, 2010, São Paulo, Brasil.

MC (Ministério das Comunicações). Programa Computadores para Inclusão: Documento Propositivo. Disponível em: < http://www.mc.gov.br/centros-de-recondicionamento-de-computadorescrcs/documentos/doc download/1161-documento-propositivo-versao-2012>. Acesso em: 15 nov. 2013.

MCTI (Ministério de Ciência, Tecnologia e Inovação). Fatores médios de emissão de CO2 grid mês ano. Disponível em: 〈http://www.mct.gov.br/index.php/content/view/321144.html\#ancora $>$. Acesso em: 09 jan. 2014.

MINGAY, S. Green IT: A New Industry Shock Wave. In: ITXPO conference, 2007, Orlando, Florida, 2007.

MOLLA, A. Organizational Motivations for Green IT: Exploring Green IT Matrix and Motivation Models. In: Pacific Asia Conference on Information Systems (PACIS), 2009, Hyderabad, India.

MURUGESAN, S. Harnessing Green IT: Principles and Practices. IT PRO, USA, p. 24-33, jan./fev. 2008.

NETO, J. Q. F.; BLOEMHOF, J. An Analysis of the Eco-Efficiency of Remanufactured Personal

Computers and Mobile Phones. Production and Operations Management. v.21, n.1, jan.- fev., 2012.

PERERA, L. C. J.; KERR, R. B.; KIMURA, H. Mecanismos De Desenvolvimento Limpo (MDL)

No Brasil-Uma Visão Ampla. In: XIII Simpósio de Administração da Produção, Logística e Operações Internacionais, 2010, São Paulo. Anais...São Paulo: Ed. FGV, 2010.

PICKAVET, M.; VEREECKEN, W.; DEMEYER, S.; AUDENAERT, P.; VERMEULEN, B.; DEVELDER, C; DEMEESTER, P. Worldwide Energy Needs for ICT: the Rise of Power-Aware Networking. In: International Symposium on Advanced Networks and Telecommunication Systems, 2., 2008, Bombay, India. New Jersey, USA: IEEE, 2008.

PORTAL BRASIL. Sistema Interligado Nacional. Disponível em:

<http://www.brasil.gov.br/sobre/economia/energia/setor-eletrico/sistema-interligado-nacional>.

Acesso em: 03 set. 2013.

PRATHER, M. J.; HSU J. $\mathrm{NF}_{3}$, the greenhouse gas missing from Kyoto. Geophysical Research Letters, v. 35, n. 12, jun. 2008.

REBITZER, G.; EKVALL, T; FRISCHKNECHT, R.; HUNKELER, D.; NORRIS, G; RYDBERG, T; SCHMIDT, W.-P.; SUH, S.; WEIDEMA, B.P.; PENNINGTON, D.W.. Life cycle assessment: Part 1: Framework, goal and scope definition, inventory analysis, and applications. Environment International. v. 30, n. 5, p. 701-720, jul. 2004.

ROESCH, S. M. A. Projetos de Estágio e de Pesquisa em Administração. 3 ed. São Paulo: Atlas, 2013, 296 p.

SAAKSVUORI, A.; IMMONEN, A. Product lifecycle management. Springer Science \& Business Media, 2008.

SEIFFERT, M. E. B. Mercado de Carbono e Protocolo de Quioto: Oportunidades de Negócio na Busca da Sustentabilidade. 2 ed. São Paulo, Atlas, 2013, 247 p. 
SINGH, G. Understanding carbon credits. 1 ed. Bombay, India. Aditya books, 2009.

SMITH, S. J.; WIGLEY, T. M. L. Global Warming Potentials: 1. Climatic Implications of Emissions Reductions. Climatic Change. v.44, n. 4, p. 445-457. 2000.

SOCOLOF, M. L.; OVERLY, J. G.; GEIBIG, Jack R. Environmental life-cycle impacts of CRT and LCD desktop computer displays. Journal of Cleaner Production, EUA, v. 13, n. 13-14, p. 1281-94, 2005.

SUDARSAN, R. et al. A product information modeling framework for product lifecycle management. Computer-aided design, v. 37, n. 13, p. 1399-1411, 2005.

TEEHAN, P.; KANDLIKAR, M. Comparing Embodied Greenhouse Gas Emissions of Modern Computing and Electronic Products. Environmental Science \& Technology. v. 47, n. 9, p. 3997-03, 2013.

TEEHAN, P.; KANDLIKAR, M. Sources of Variation in Life Cycle Assessments of Desktop Computers. Journal of Industrial Ecology. v.16, s. 1, p. 182-94. 2012.

UNEP. LIFE CYCLE MANAGEMENT: A Business Guide to Sustainability

Disponível em: <http://www.unep.org/pdf/dtie/DTI0889PA.pdf> Acesso em: 30 Ago. 2015.

UNFCCC. Global Warming Potentials. Disponível em: <http://unfccc.int/ghg data/items/3825.php> Acesso em: 10 mai. 2013.

WILLIAMS, E. Environmental effects of information and communications technologies. Nature, v. 479, n. 17, p. 354-58, 2011.

WILLIAMS, E.; SASAKI, Y.. Energy Analysis of End-of-life Options for Personal Computers: Resell, Upgrade, Recycle. In: IEEE International Symposium on Electronics and the Environment, 2003, Piscataway, New Jersey, EUA: IEEE, p. 187-92, 2003.

XAVIER, L. H.; LUCENA, L. C.; COSTA, M. D.; XAVIER, V. A.; CARDOSO, R. S. Gestão de Resíduos Eletroeletrônicos: Mapeamento da Logística Reversa de Computadores e Componentes no Brasil. In: $3^{\circ}$ Simposio Iberoamericano de Ingeniería de Residuos, 2010, João Pessoa, Paraíba, Brasil.

XAVIER, L. H.; CORRÊA, H. L. Sistemas de Logística Reversa: Criando Cadeias de Suprimentos Sustentáveis. São Paulo, Atlas, 2013, 265 p.

YAO, M. A.; HIGGS, T. G.; CULLEN, M. J.; STEWART, S.; BRADY, T. A. Comparative Assessment of Life Cycle Assessment Methods Used for Personal Computers. Environmental Science \& Technology. v. 44, n. 19, p 7335-46, 2010.

YIN, R. K. Case Study Research: Design and Methods. 3. ed. EUA: Sage Publications, 2003, 312 p.

APÊNDICE A - Instrumento para coleta de dados 
Entrevistado:

Entrevistador:

Data: Local:

Rapport:

"Prezado Sr. , somos pesquisadores da PUCRS e estamos pesquisando os benefícios das atividades do CRC-CESMAR. Vamos fazer algumas perguntas e desejamos saber se podemos gravar nossa conversa.(aguardar aceite)

Também anotaremos alguns aspectos principais. Ok? Podemos começar?

Perguntas:

1. Existem dados históricos sobre a quantidade de equipamentos recondicionados por mês?

a) Quantos computadores o CRC-CESMAR recondiciona por mês?

b) Quantos monitores LCD e CRT são reaproveitados por mês?

c) O que é feito com os equipamentos recondicionados? Para onde são enviados?

2. Como o CESMAR faz o controle da quantidade e do tipo de equipamento enviados para as instituições beneficiadas?

3. Os dados históricos contemplam as especificações do equipamento doado? Como por exemplo, o tipo de processador, a quantidade de memória RAM, o espaço de armazenagem no disco rígido, a unidade ótica como drives de CD ou DVD, potência de saída da fonte,etc?

4. Existe uma configuração padrão mínima para o equipamento recondicionado? Como por exemplo, processador Intel Pentium 4, placa mãe com placa de vídeo e som onboard, 1GB de RAM, 250 GB de armazenamento em disco, DVD?

5. Existe algum compromisso do CRC-CESMAR para reparos e manutenção dos computadores com as instituições? Como funciona?

6. Qual a média mensal de custos com energia elétrica para a realização do trabalho de recondicionamento de computadores? Por exemplo, iluminação do ambiente, equipamentos, teste de máquinas, etc.

7. O que é feito com as peças que não podem ser reaproveitadas e não podem ser recicladas integralmente no estado como placas-mãe defeituosas e monitores queimados?

APÊNDICE B - Instrumento para coleta de dados 
Entrevistado:

Entrevistador:

Data: Local:

Rapport:

"Prezado $\operatorname{Sr}(a)$. somos pesquisadores da PUCRS estamos pesquisando sobre os benefícios das atividades do CRC-CESMAR. Vou fazer algumas perguntas e desejamos saber se podemos gravar nossa conversa. (aguardar aceite) Também anotaremos alguns aspectos principais. Ok? Podemos começar?

Perguntas:

1. Qual a média de horas por dia que os equipamentos doados pelo CRC-CESMAR são utilizados na instituição? Quantos dias por semana os computadores são utilizados?

No caso de uma instituição de ensino pública, durante o período de férias os computadores permanecem em uso?

2. Quantos anos em média os equipamentos doados pelo CRC-CESMAR são usados pela instituição antes de serem descartados?

3. Quantos equipamentos doados estão em operação atualmente? 
APÊNDICE C - Instrumento para coleta de dados

REGISTRO DE PESQUISA DOCUMENTAL DOS EQUIPAMENTOS RECONDICIONADOS PELO CRC CESMAR

\begin{tabular}{|c|c|c|c|c|c|c|c|c|c|c|c|c|c|c|c|c|c|c|c|c|c|c|c|c|}
\hline EQUIPAMENTD & \multicolumn{12}{|c|}{2010} & \multicolumn{12}{|c|}{2012} \\
\hline & J & $\mathrm{F}$ & M & A & M & $\mathrm{J}$ & $\mathrm{J}$ & A & S & $\mathrm{O}$ & $\mathrm{N}$ & D & $\mathrm{J}$ & $\mathrm{F}$ & M & A & M & $\mathbf{J}$ & $\mathrm{J}$ & A & S & $\mathrm{O}$ & $\mathrm{N}$ & D \\
\hline PC & & & & & & & & & & & & & & & & & & & & & & & & \\
\hline $\begin{array}{c}\text { MONITOR } \\
\text { CRT }\end{array}$ & & & & & & & & & & & & & & & & & & & & & & & & \\
\hline $\begin{array}{l}\text { ENTIDADE } \\
S\end{array}$ & & & & & & & & & & & & & & & & & & & & & & & & \\
\hline CONTATOS & & & & & & & & & & & & & & & & & & & & & & & & \\
\hline
\end{tabular}

\begin{tabular}{|c|c|c|c|c|c|c|c|c|c|c|c|c|}
\hline ANO & \multicolumn{12}{|c|}{2013} \\
\hline & $\mathrm{J}$ & $\mathrm{F}$ & $\mathrm{M}$ & A & $\mathrm{M}$ & $\mathrm{J}$ & $\mathrm{J}$ & A & S & $\mathrm{O}$ & $\mathrm{N}$ & $\mathrm{D}$ \\
\hline PC & & & & & & & & & & & & \\
\hline MONITOR CRT & & & & & & & & & & & & \\
\hline ENTIDADES & & & & & & & & & & & & \\
\hline CONTATOS & & & & & & & & & & & & \\
\hline
\end{tabular}

APÊNDICE D - Lista de conjuntos de equipamentos entregues e entidades beneficiadas 


\begin{tabular}{|c|c|c|}
\hline ENTIDADE & DATA DE ENTREGA & $\mathbf{N}^{\circ}$ CPUS \\
\hline & 2010 & \\
\hline LBV - PORTO ALEGRE & $08 / 03 / 2010$ & 15 \\
\hline AMA - ASSOC AMIGOS DO MEIO AMBIENTE & $12 / 04 / 2010$ & 5 \\
\hline GUARDA MUNICIPAL DE CANOAS & $11 / 05 / 2010$ & 5 \\
\hline SEC.BEM ESTAR -C.CANOA & $25 / 05 / 2010$ & 20 \\
\hline PASTORAL CAPÃO DA CANOA & $25 / 5 / 2010$ & 10 \\
\hline ESC. EST PROF G.VIEGAS & $26 / 5 / 2010$ & 10 \\
\hline COL EST AFONSO MASSOT & $26 / 05 / 2010$ & 10 \\
\hline \begin{tabular}{|l|} 
ESC.HELENA SCHNEIDER \\
\end{tabular} & $27 / 05 / 2010$ & 10 \\
\hline ESC.E.HENRIQUE FARJAT & $01 / 06 / 2010$ & 10 \\
\hline SOME - SOC. M. EDUCAÇÃO & $01 / 06 / 2010$ & 5 \\
\hline ASSOCIAÇÃO ILÊ MULHER & $16 / 06 / 2010$ & 10 \\
\hline PROCEPA - PROG SOCIAL & $18 / 06 / 2010$ & 10 \\
\hline CENTRO SOCIAL MARISTA IRMÃO DONATO & $16 / 07 / 2010$ & 10 \\
\hline ESC DE ED. GENTIL VIEGAS & $16 / 07 / 2010$ & 10 \\
\hline COMUNIDADE TERAPÊUTICA ZÉ MARIA - São Leopoldo & $20 / 07 / 2010$ & 10 \\
\hline OBRA IMACULADO - OSICOM & $20 / 07 / 2010$ & 20 \\
\hline ONG SUVE SOC. UNIÃO & $22 / 07 / 2010$ & 1 \\
\hline CENTRO MARISTA I. EMILIO Lajeado/RS & $23 / 08 / 2010$ & 10 \\
\hline SEC.MUNIC.TRAMANDAÍ & $22 / 08 / 2010$ & 10 \\
\hline MINISTÉRIO PÃO VIVO & $30 / 08 / 2010$ & 10 \\
\hline COLÉGIO M. VETTORELLO & $31 / 08 / 2010$ & 8 \\
\hline \multirow[t]{3}{*}{ CENTRO INF. RENASCER ESPERANÇA } & $09 / 09 / 2010$ & 5 \\
\hline & & 214 \\
\hline & 2012 & \\
\hline SOCIEDADE ESPÍRITA LAR DE JESUS & $06 / 03 / 2012$ & 10 \\
\hline A. M. DA VILA BRÁS & $09 / 03 / 2012$ & 10 \\
\hline P.M NOVA RAMADA & $14 / 03 / 2012$ & 10 \\
\hline C.M.C.E INCLUSÃO DIGITAL & $14 / 03 / 2012$ & 10 \\
\hline P.M. CAIÇARA & $15 / 03 / 2012$ & 10 \\
\hline P.M BARRA DO RIO AZUL & $19 / 03 / 2012$ & 10 \\
\hline P.M. SÃO JOSÉ DO SUL & $27 / 03 / 2012$ & 10 \\
\hline P.M. ENCANTADO & $27 / 03 / 2012$ & 10 \\
\hline P.M LAGOA DOS TRÊS CANTOS & $28 / 03 / 2012$ & 10 \\
\hline P.M. MATO LEITÃO & $10 / 04 / 2012$ & 10 \\
\hline P.M CORONEL BICAÇO & $10 / 04 / 2012$ & 10 \\
\hline P.M. RESTINGA SECA & $10 / 04 / 2012$ & 10 \\
\hline P.M. PINHAL GRANDE & $10 / 04 / 2012$ & 10 \\
\hline P.M. EUGENIO DE CASTRO & $11 / 04 / 2012$ & 10 \\
\hline P.M. TUPANCIRETÃ & $18 / 04 / 2012$ & 10 \\
\hline PÃO DOS POBRES & $10 / 05 / 2012$ & 10 \\
\hline P.M. PORTÃO & $11 / 05 / 2012$ & 10 \\
\hline P.M MARQUES DE SOUSA & $16 / 05 / 2012$ & 10 \\
\hline P.M. PAVERAMA & $21 / 05 / 2012$ & 10 \\
\hline CRECHE MADRE TEREZA & $25 / 05 / 2012$ & 10 \\
\hline P.M. SÃO LEOPOLDO & $28 / 05 / 2012$ & 10 \\
\hline CENTRO INF. FAVO DE MEL & $28 / 05 / 2012$ & 10 \\
\hline A. A. ZUMBI DOS PALMARES & $13 / 06 / 2012$ & 10 \\
\hline P.M. CERRO BRANCO & $22 / 06 / 2012$ & 10 \\
\hline AVESOL & $01 / 08 / 2012$ & 5 \\
\hline P.M. TRINDADE DO SUL & $08 / 08 / 2012$ & 5 \\
\hline CAGERS - Contadoria e Auditoria-Geral do Estado do RS & $01 / 10 / 2012$ & 10 \\
\hline \multirow[t]{3}{*}{ APE NONOAI } & $26 / 10 / 2012$ & 10 \\
\hline & & 270 \\
\hline & 2013 & \\
\hline ASSOCIAÇÃO DE PAIS E AMIGOS -APE & $06 / 05 / 2013$ & 6 \\
\hline CENTRO SOCIAL CRISTO É VIDA & $27 / 06 / 2013$ & 11 \\
\hline SINDICATO DOS TRABALHADORES RURAIS DE CONSTANTINA & $29 / 06 / 2013$ & 11 \\
\hline P.M. ESTEIO & $29 / 07 / 2013$ & 11 \\
\hline \multirow{2}{*}{ AMIGOS DA ESCOLINHA COMUNITÁRIA CRIANÇAS DO FUTURO } & 05/09/2013 & 11 \\
\hline & & 50 \\
\hline
\end{tabular}

Fonte: Ministério Público do Rio Grande do Sul (2013) 
APÊNDICE E - Emissões diretas para o trabalho de recondicionamento
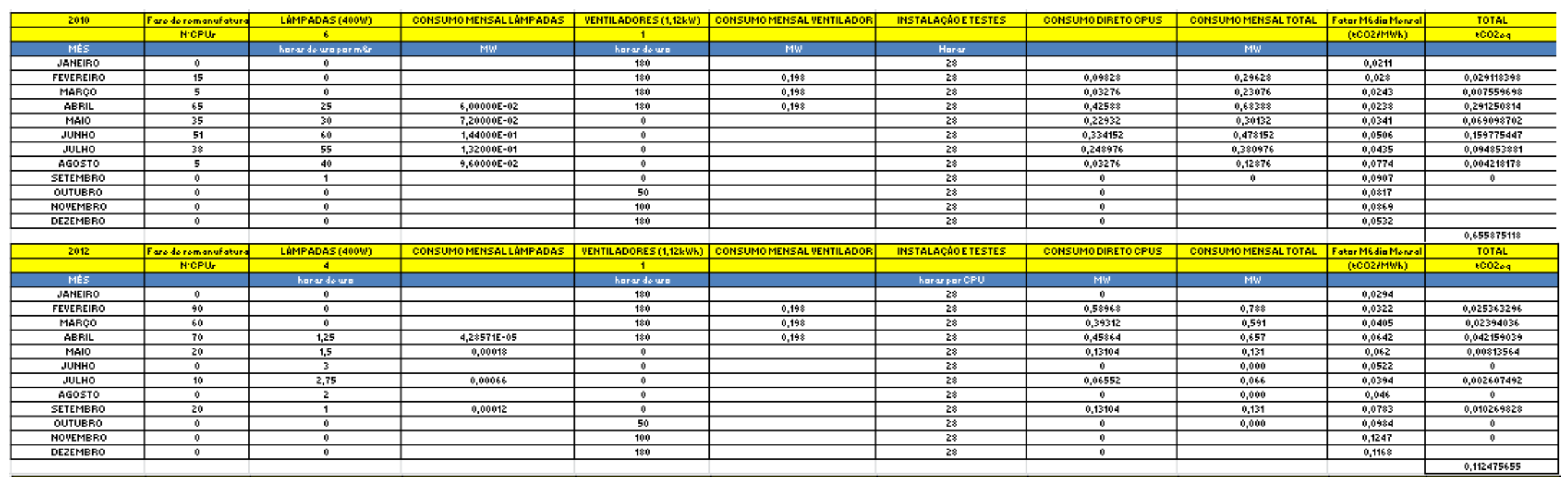

\begin{tabular}{|c|c|c|c|c|c|c|c|c|c|c|}
\hline 2013 & Farcideromanuffotura & LÁMPADAS $(4000 W)$ & CONSUMOMENSALLÁMPADAS & \begin{tabular}{|l} 
WENTILADORES $(1,12 \mathrm{kWh})$ \\
\end{tabular} & COHSUMOMENSAL MEHTILADOR & INSTALACCÁOE TESTES & CONSUMODIRETOCFUS & CONSUMOMENSAL TOTAL & Fatar M6dia Mensal & TOTAL \\
\hline & N-CFUr & 4 & $M W$ & \begin{tabular}{|c}
1 \\
\end{tabular} & $M W$ & & & & $(\mathrm{ecoz} M \mathrm{MWh})$ & 400204 \\
\hline MES & & harardowa & & hararde wera & & & & $M W$ & & \\
\hline JAMEIFO & 0 & 0 & & 130 & & 28 & 0 & & 0,4151 & \\
\hline FEMEREIFO & 0 & 0 & & $1 \leqslant 0$ & & 28 & $\frac{0}{0}$ & & 0,109 & \\
\hline MARCOO & 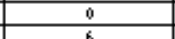 & $\frac{0}{1.25}$ & & 180 & & $\frac{23}{23}$ & $\frac{0}{0,039312}$ & 0.037312 & $0,09 \% 1$ & \\
\hline AEFil & $\frac{6}{22}$ & 1,25 & 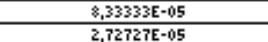 & $\frac{1 \$ 0}{0}$ & 0,198 & $\frac{28}{28}$ & $0.0,039412$ & $\frac{0,237312}{0,142273333}$ & 0,0959 & $0,02275 \div 2211$ \\
\hline MUAIHO & $\frac{21}{11}$ & $\frac{1,5}{3}$ & $\frac{1,261212-109}{0,006109091}$ & 0 & & 28 & 0,072072 & $\frac{0,01942 \angle 3535}{0,072099273}$ & $\frac{0,1151}{0,1079}$ & $0,0,06777795656$ \\
\hline JULHO & 0 & 2,75 & & 0 & & 28 & 0 & 0,060109091 & $\frac{0,0838}{0.083}$ & $9,14132 E-06$ \\
\hline AGOSTOO & 11 & 2 & $7,27273 E-05$ & 0 & & 28 & 0,072072 & 0,072144727 & 0,0633 & 0,0060099656 \\
\hline SETEMERO & & 1 & & 0 & & 28 & (n) & & & 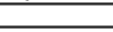 \\
\hline
\end{tabular}


APÊNDICE F - Emissões dos equipamentos da configuração 1 de 2006 a 2009

\begin{tabular}{|c|c|c|c|c|c|c|c|c|c|c|c|}
\hline 2006 & $1^{2}$ Fase de uso ${ }^{*}$ & & & Média anual (tCO2MWh) & & 2007 & $1^{2}$ Fase de uso* & & & Média anual (tCO2MWh) & \\
\hline & CPUS & AGREGADO & Horas vtilizadas** & Média anual 0,0323 & $\mathrm{CO} 2 \mathrm{eg}(\mathrm{t})$ & & CPUS & AGREGADO & Horas vitilizadas** & Média anual 0,0293 & $\mathrm{CO} 2 \mathrm{eg}(\mathrm{t})$ \\
\hline MES & & & & Mensal a & & MESS & & & & Mensal & \\
\hline JANEIRO & 15 & 15 & 190 & 0,0322 & 0,02147418 & JANEIRO & 0 & 214 & 190 & 0,0229 & 0,217880676 \\
\hline FEVEREIRO & 5 & 20 & 190 & 0,0346 & 0,03076632 & FEVEREIRO & 0 & 214 & 190 & 0,0195 & 0,18553158 \\
\hline MARÇO & 65 & 85 & 190 & 0,0337 & 0,12735567 & MARÇO & 0 & 214 & 190 & 0,0195 & 0,18553158 \\
\hline ABRIL & 35 & 120 & 190 & 0,0275 & 0,146718 & ABRIL & 0 & 214 & 190 & 0,0197 & 0,187434468 \\
\hline MAIO & 51 & 171 & 190 & 0,0317 & 0,241004322 & MAIO & 0 & 214 & 190 & 0,0161 & 0,153182484 \\
\hline JUNHO & 38 & 209 & 190 & 0,0306 & 0,284339484 & JUNHO & 0 & 214 & 190 & 0,0256 & 0,243569664 \\
\hline JULHO & 5 & 214 & 190 & 0,0351 & 0,333956844 & ЛLLHO & 0 & 214 & 190 & 0,031 & 0,29494764 \\
\hline AGOSTO & 0 & 214 & 190 & 0,0336 & 0,319685184 & AGOSTO & 0 & 214 & 190 & 0,0324 & 0,308267856 \\
\hline SETEMBRO & 0 & 214 & 190 & 0,0383 & 0,364403052 & SETEMBRO & 0 & 214 & 190 & 0,0355 & 0,33776262 \\
\hline OUTUBRO & 0 & 214 & 190 & 0,036 & 0,34251984 & OUTUBRO & 0 & 214 & 190 & 0,0377 & 0,358694388 \\
\hline NOVEMBRO & 0 & 214 & 190 & 0,0265 & 0,25213266 & NOVEMBRO & 0 & 214 & 190 & 0,0406 & 0,386286264 \\
\hline \multirow[t]{2}{*}{ DEZEMBRO } & 0 & 214 & 190 & 0,028 & 0,26640432 & DEZEMBRO & 0 & 214 & 190 & 0,0496 & 0,471916224 \\
\hline & & & & & 2,730759876 & & & & & & 3,331005444 \\
\hline \multirow[t]{2}{*}{2008} & $1^{2}$ Fase de uso ${ }^{*}$ & & & Média anual (tCO2MWh) & & 2009 & $1^{2}$ Fase de uso ${ }^{*}$ & & & Média anval (tCO2MWh) & \\
\hline & CPUS & AGREGADO & Horas vtilizadas** & Média anual 0,0484 & $\mathrm{CO} 2 \mathrm{eg}(\mathrm{t})$ & & CPUS & AGREGADO & Horas vtilizadas** & Média anual 0,0246 & $\mathrm{CO} 2 \mathrm{eg}(\mathrm{t})$ \\
\hline MESS & & & & FCMensal & & MESS & & & & Mensal & \\
\hline JANEIRO & 90 & 304 & 190 & 0,0584 & 0,789325056 & JANEIRO & 0 & 484 & 190 & 0,0281 & 0,604673784 \\
\hline FEVEREIRO & 60 & 364 & 190 & 0,0668 & 1,081053792 & FEVEREIRO & 0 & 484 & 190 & 0,0237 & 0,509991768 \\
\hline MARÇO & 70 & 434 & 190 & 0,0599 & 1,155808836 & MARÇO & 6 & 490 & 190 & 0,0247 & 0,53809938 \\
\hline ABRIL & 20 & 454 & 190 & 0,0453 & 0,914373252 & ABRIL & 22 & 512 & 190 & 0,0245 & 0,55770624 \\
\hline MAIO & 0 & 454 & 190 & 0,0459 & 0,926484156 & MAIO & 11 & 523 & 190 & 0,0405 & 0,94172949 \\
\hline JUNHO & 10 & 464 & 190 & 0,0521 & 1,074793824 & JUNHO & 0 & 523 & 190 & 0,0369 & 0,858020202 \\
\hline JULHO & 0 & 464 & 190 & 0,0437 & 0,901506528 & ЛLHO & 11 & 534 & 190 & 0,0241 & 0,572173524 \\
\hline AGOSTO & 20 & 484 & 190 & 0,0425 & 0,9145422 & AGOSTO & 0 & 534 & 190 & 0,0199 & 0,472458636 \\
\hline SETEMBRO & 0 & 484 & 190 & 0,0411 & 0,884416104 & SETEMBRO & 0 & 534 & 190 & 0,0162 & 0,384614568 \\
\hline OUTUBRO & 0 & 484 & 190 & 0,0438 & 0,942516432 & OUTUBRO & 0 & 534 & 190 & 0,0179 & 0,424975356 \\
\hline NOVEMBRO & 0 & 484 & 190 & 0,0334 & 0,718722576 & NOVEMBRO & 0 & 534 & 190 & 0,0181 & 0,429723684 \\
\hline DEZEMBRO & 0 & 484 & 190 & 0,0477 & 1,026439128 & DEZEMBRO & 0 & 534 & 190 & 0,0194 & 0,460587816 \\
\hline & & & & & 11,32998188 & & & & & & 6,754754448 \\
\hline
\end{tabular}


APÊNDICE G - Emissões dos equipamentos da configuração 1 de 2010 a 2013

\begin{tabular}{|c|c|c|c|c|c|c|c|c|c|}
\hline 2010 & $1^{2}$ Fase de uso & & (tCO2 $\mathrm{MWh})$ & & 2011 & 1? Fase de uso & & $(\mathrm{tCO} 2 / \mathrm{MWh})$ & \\
\hline & CPUS & AGREGADO & 0,0512 & & & CPUS & AGREGADO & 0,0292 & \\
\hline MESS & & & Fator Médio Mensal & co2eq(t) & MÊS & & & Fator Médio Mensal & CO2eq(t) \\
\hline JANEIRO & 15 & 519 & 0,0211 & 0,486877014 & JANEIRO & 0 & 320 & 0,0262 & 0,37275264 \\
\hline FEVEREIRO & 5 & 514 & 0,028 & 0,63986832 & FEVEREIRO & 0 & 320 & 0,0288 & 0,40974336 \\
\hline MARÇO & 65 & 449 & 0,0243 & 0,485089722 & MARC̣O & 0 & 320 & 0,0208 & 0,29592576 \\
\hline ABRIL & 35 & 414 & 0,0238 & 0,438073272 & ABRIL & 0 & 320 & 0,0198 & 0,28169856 \\
\hline MAIO & 51 & 363 & 0,0341 & 0,550339218 & MAIO & 0 & 320 & 0,027 & 0,3841344 \\
\hline JUNHO & 38 & 325 & 0,0506 & |0,7311447 & JUNHO & 0 & 320 & 0,0341 & 0,48514752 \\
\hline JULHO & 5 & 320 & 0,0435 & 0,6188832 & JULHO & 0 & 320 & 0,0308 & 0,43819776 \\
\hline AGOSTO & 0 & 320 & 0,0774 & 1,10118528 & AGOSTO & 0 & 320 & 0,0301 & 0,42823872 \\
\hline SETEMBRO & 0 & 320 & 0,0907 & 1,29040704 & SETEMBRO & 0 & 320 & 0,0273 & 0,38840256 \\
\hline OUTUBRO & 0 & 320 & 0,0817 & 1,16236224 & OUTUBRO & 0 & 320 & 0,035 & 0,497952 \\
\hline NOVEMBRO & 0 & 320 & 0,0869 & 1,23634368 & NOVEMBRO & 0 & 320 & 0,0356 & 0,50648832 \\
\hline \multirow[t]{2}{*}{ DEZEMBRO } & 0 & 320 & 0,0532 & 0,75688704 & DEZEMBRO & 0 & 320 & 0,0349 & 0,49652928 \\
\hline & & & & 9,497460726 & & & & & 4,98521088 \\
\hline \multirow[t]{2}{*}{2012} & 12 Fase de uso & & $(\mathrm{tCO} 2 / \mathrm{MWh})$ & & 2013 & 1? Fase de uso & & Média anual & \\
\hline & CPUS & AGREGADO & 0,0653 & & & CPUS & AGREGADO & 0,09445 & \\
\hline MÊs & & & Fator Médio Mensal & co2eq $(\mathrm{t})$ & MÊS & & & Fator MédioMensal & CO2eq(t) \\
\hline JANEIRO & 90 & 230 & 0,0294 & 0,30063852 & JANEIRO & 0 & 50 & 0,1151 & 0,2558673 \\
\hline FEVEREIRO & 60 & 170 & 0,0322 & 0,24337404 & FEVEREIRO & 0 & 50 & 0,109 & 0,242307 \\
\hline MARC̦O & 70 & 100 & 0,0405 & 0,180063 & MARÇO & 6 & 44 & 0,0981 & 0,191907144 \\
\hline ABRIL & 20 & 80 & 0,0642 & 0,22834656 & ABRIL & 22 & 22 & 0,0959 & 0,093801708 \\
\hline MAIO & 0 & 80 & 0,062 & 0,2205216 & MAIO & 11 & 11 & 0,1151 & 0,056290806 \\
\hline JUNHO & 10 & 70 & 0,0522 & 0,16245684 & JUNHO & 0 & 11 & 0,1079 & 0,052769574 \\
\hline JULHO & 0 & 70 & 0,0394 & 0,12262068 & JULHO & 11 & 0 & 0,0838 & 0 \\
\hline AGOSTO & 20 & 50 & 0,046 & 0,102258 & AGOSTO & 0 & 0 & 0,08330 & 0 \\
\hline SETEMBRO & 0 & 50 & 0,0783 & 0,1740609 & SETEMBRO & 0 & 0 & 0,08400 & 0 \\
\hline OUTUBRO & 0 & 50 & 0,0984 & 0,2187432 & OUTUBRO & 0 & 0 & 0,08310 & 0 \\
\hline NOVEMBRO & 0 & 50 & 0,1247 & 0,2772081 & NOVEMBRO & 0 & 0 & 0,09300 & 0 \\
\hline DEZEMBRO & 0 & 50 & 0,1168 & 0,2596464 & DEZEMBRO & 0 & 0 & 0,08410 & 0 \\
\hline & & & & 2,48993784 & & & & & 0,892943532 \\
\hline
\end{tabular}


APÊNDICE H - Emissões dos equipamentos da configuração 1 recondicionados de 2010 a 2013

\begin{tabular}{|c|c|c|c|c|c|c|c|c|c|}
\hline 2010 & $2^{2}$ Fase de uso & & (tCO2MWh) & & 2011 & 2: Fase de uso & & (tCO2/MWh) & \\
\hline & CPUS REMANUFATURADOS & AGREGADO & 0,0512 & $\mathrm{CO} 2 \mathrm{eg}(\mathrm{t})$ & & CPUS REMANUFATURADOS & AGREGADO & 0,0292 & CO2eq $(\mathrm{t})$ \\
\hline MÉS & & & Fator Médio Mensal & & MÊSS & & & Fator Médio Mensal & \\
\hline JANEIRO & 0 & 0 & 0,0211 & 0 & JANEIRO & 0 & 214 & 0,0262 & 0,209918592 \\
\hline FEVEREIRO & 0 & 0 & 0,028 & 0 & FEVEREIRO & 0 & 214 & 0,0288 & 0,230750208 \\
\hline MARÇO & 15 & 15 & 0,0243 & 0,01364688 & MARÇO & 0 & 214 & 0,0208 & 0,166652928 \\
\hline ABRIL & 5 & 20 & 0,0238 & 0,01782144 & ABRIL & 0 & 214 & 0,0198 & 0,158640768 \\
\hline MAIO & 65 & 85 & 0,0341 & 0,10851984 & MAIO & 0 & 214 & 0,027 & 0,21632832 \\
\hline JNHO & 35 & 120 & 0,0506 & 0,22733568 & JUNHO & 0 & 214 & 0,0341 & 0,273214656 \\
\hline JULHO & 51 & 171 & 0,0435 & 0,27849744 & JULHO & 0 & 214 & 0,0308 & 0,246774528 \\
\hline AGOSTO & 38 & 209 & 0,0774 & 0,605651904 & AGOSTO & 0 & 214 & 0,0301 & 0,241166016 \\
\hline SETEMBRO & 5 & 214 & 0,0907 & 0,726702912 & SETEMBRO & 0 & 214 & 0,0273 & 0,218731968 \\
\hline OUTUBRO & 0 & 214 & 0,0817 & 0,654593472 & OUTUBRO & 0 & 214 & 0,035 & 0,2804256 \\
\hline NOVEMBRO & 0 & 214 & 0,0869 & 0,696256704 & NOVEMBRO & 0 & 214 & 0,0356 & 0,285232896 \\
\hline \multirow[t]{2}{*}{ DEZEMBRO } & 0 & 214 & 0,0532 & 0,426246912 & DEZEMBRO & 0 & 214 & 0,0349 & 0,279624384 \\
\hline & & & & 3,755273184 & & & & & 2,807460864 \\
\hline \multirow[t]{2}{*}{2012} & 2: Fase de uso & & $(\mathrm{tCO} 2 / \mathrm{MWh})$ & & 2013 & 2: Fase de uso & & Média anual (tc02/MWh) & \\
\hline & CPUS REMANUFATURADOS & AGREGADO & 0,0653 & CO2eq(t) & & CPUS REMANUFATURADOS & AGREGADO & 0,09445 & CO2eq $(\mathrm{t})$ \\
\hline MÊS & & & Fator Médio Mensal & & MÊs & & & Mensal & \\
\hline JANEIRO & 0 & 214 & 0,0294 & 0,235557504 & JANEIRO & 0 & 484 & 0,1151 & 2,085722496 \\
\hline FEVEREIRO & 0 & 214 & 0,0322 & 0,257991552 & FEVEREIRO & 0 & 484 & 0,109 & 1,97518464 \\
\hline MARC̦O & 90 & 304 & 0,0405 & 0,46096128 & MARCSO & 0 & 484 & 0,0981 & 1,777666176 \\
\hline ABRIL & 60 & 364 & 0,0642 & $\begin{array}{l}0,874927872 \\
\end{array}$ & ABRIL & 0 & 484 & 0,0959 & 1,737800064 \\
\hline MAIO & 70 & 434 & 0,062 & 1,00743552 & MAIO & 6 & 490 & 0,1151 & 2,11157856 \\
\hline JUNHO & 20 & 454 & 0,0522 & 0,887283072 & JUNHO & 22 & 512 & 0,1079 & 2,068365312 \\
\hline JULHO & 0 & 454 & 0,0394 & 0,669711744 & JULHO & 11 & 523 & 0,0838 & 1,640897856 \\
\hline AGOSTO & 10 & 464 & 0,046 & 0,79911936 & AGOSTO & 0 & 523 & 0,08330 & 1,631107296 \\
\hline SETEMBRO & 0 & 464 & 0,0783 & 1,360240128 & SETEMBRO & 11 & 534 & 0,08400 & 1,67940864 \\
\hline OUTUBRO & 20 & 484 & 0,0984 & 1,783102464 & OUTUBRO & 0 & 534 & 0,08310 & 1,661414976 \\
\hline NOVEMBRO & 0 & 484 & 0,1247 & 2,259683712 & NOVEMBRO & 0 & 534 & 0,09300 & 1,85934528 \\
\hline DEZEMBRO & 0 & 484 & 0,1168 & 2,116528128 & DEZEMBRO & 0 & 534 & 0,08410 & 1,681407936 \\
\hline & & & & 12,71254234 & & & & & 21,90989923 \\
\hline
\end{tabular}


APÊNDICE I - Emissões projetadas dos equipamentos da configuração 1 recondicionados de 2014 a 2017

\begin{tabular}{|c|c|c|c|c|c|c|c|c|c|}
\hline 2014 & 2: Fase de uso & & Média anual (tCO2/MWh) & & 2015 & 2: Fase de uso & & Média anual (tCO2/MWh) & \\
\hline & CPUS REMANUFATURADOS & AGREGADO & & CO2eq $(\mathrm{t})$ & & CPUS REMANUFATURADOS & AGREGADO & & CO2eq $(\mathrm{t})$ \\
\hline MÊS & & & Mensal & & MÊS & & & Mensal & \\
\hline JANEIRO & 0 & 534 & 0,05690 & 1,137599424 & JANEIRO & 0 & 320 & 0,06713 & 0,80431104 \\
\hline FEVEREIRO & 0 & 534 & 0,05667 & 1,1329344 & FEVEREIRO & 0 & 320 & 0,06596 & 0,79020032 \\
\hline MARÇO & 0 & 534 & 0,05313 & 1,062292608 & MARÇO & 0 & 320 & 0,06391 & 0,76570624 \\
\hline ABRIL & 0 & 519 & 0,05997 & 1,165233888 & ABRIL & 0 & 320 & 0,07336 & 0,87885824 \\
\hline MAIO & 0 & 514 & 0,06803 & 1,309244352 & MAIO & 0 & 320 & 0,08171 & 0,97896448 \\
\hline JUNHO & 0 & 449 & 0,06473 & 1,088203584 & JUNHO & 0 & 320 & 0,07494 & 0,8978944 \\
\hline JULHO & 0 & 414 & 0,05133 & 0,79567488 & JULHO & 0 & 320 & 0,05818 & 0,69701632 \\
\hline AGOSTO & 0 & 363 & 0,05313 & 0,722120256 & AGOSTO & 0 & 320 & 0,06081 & 0,72856576 \\
\hline SETEMBRO & 0 & 325 & 0,06320 & 0,7690176 & SETEMBRO & 0 & 320 & 0,07517 & 0,9005568 \\
\hline OUTUBRO & 0 & 320 & 0,07217 & 0,8646144 & OUTUBRO & 0 & 320 & 0,08456 & 1,0130432 \\
\hline NOVEMBRO & 0 & 320 & 0,08443 & 1,01157888 & NOVEMBRO & 0 & 320 & 0,10071 & 1,20659968 \\
\hline \multirow[t]{2}{*}{ DEZEMBRO } & 0 & 320 & 0,07860 & 0,94169088 & DEZEMBRO & 0 & 320 & 0,09317 & 1,1162112 \\
\hline & & & & 12,00020515 & & & & & 10,77792768 \\
\hline \multirow[t]{2}{*}{2016} & 23 Fase de uso & & Média anual (tCO2/MWh) & & 2017 & 2! Fase de uso & & Média anual (tCO2/MWh) & \\
\hline & CPUS REMANUFATURADOS & AGREGADO & & CO2eq $(\mathrm{t})$ & & CPUS REMANUFATURADOS & AGREGADO & & $\mathrm{CO} 2 \mathrm{eq}(\mathrm{t})$ \\
\hline MÊs & & & Mensal & & MÊS & & & Mensal & \\
\hline JANEIRO & 0 & 320 & 0,07971 & 0,95500288 & JANEIRO & 0 & 50 & 0,06791 & 0,127136533 \\
\hline FEVEREIRO & 0 & 320 & $0,0,07721$ & 0,925006507 & FEVEREIRO & 0 & 50 & 0,06661 & 0,124693689 \\
\hline MARÇO & 0 & 320 & 0,07171 & 0,859200853 & MARÇO & 0 & 50 & 0,06292 & 0,117785778 \\
\hline ABRIL & 0 & 230 & 0,07641 & 0,657959467 & ABRIL & 0 & 50 & 0,06991 & 0,130871289 \\
\hline MAIO & 0 & 170 & 0,08828 & 0,561893973 & MAIO & 0 & 50 & 0,07934 & 0,148528178 \\
\hline JUNHO & 0 & 100 & 0,08253 & 0,308977067 & JUNHO & 0 & 44 & 0,07407 & 0,122016498 \\
\hline JULHO & 0 & 80 & 0,06444 & 0,193001813 & JULHO & 0 & 22 & 0,05798 & 0,047759204 \\
\hline AGOSTO & 0 & 80 & 0,06575 & 0,196928853 & AGOSTO & 0 & 11 & 0,05990 & 0,024668199 \\
\hline SETEMBRO & 0 & 70 & 0,07412 & 0,19425952 & SETEMBRO & 0 & 11 & 0,07083 & 0,029170475 \\
\hline OUTUBRO & 0 & 70 & 0,07994 & 0,209508693 & OUTUBRO & 0 & 0 & 0,07889 & 0 \\
\hline NOVEMBRO & 0 & 50 & 0,09271 & 0,173562133 & NOVEMBRO & 0 & 0 & 0,09262 & 0 \\
\hline \multirow[t]{2}{*}{ DEZEMBRO } & 0 & 50 & 0,08529 & 0,1596608 & DEZEMBRO & 0 & 0 & 0,08569 & 0 \\
\hline & & & & 5,39496256 & & & & & 0,872629842 \\
\hline
\end{tabular}


APÊNDICE J - Emissões dos equipamentos da configuração 2 de 2010 a 2013

\begin{tabular}{|c|c|c|c|c|c|c|c|c|c|}
\hline 2010 & Fase de uso & & $(\mathrm{tCO} 2 \mathrm{MWh})$ & & 2011 & Fase de uso & & (tCO2/MWh) & \\
\hline & CPUS CONFIGURAÇÃO 2 & AGREGADO & 0,0512 & $\mathrm{CO} 2 \mathrm{eg}(\mathrm{t})$ & & CPUS CONFIGURAÇÃO 2 & AGREGADO & 0,0292 & $\mathrm{CO}_{\mathrm{eg}}(\mathrm{t})$ \\
\hline MÉS & & & Fator Médio Mensal & & MÉS & & & Fator Médio Mensal & \\
\hline JANEIRO & 0 & 0 & 0,0211 & 0 & JANEIRO & 0 & 214 & 0,0262 & 0,175201286 \\
\hline FEVEREIRO & 0 & 0 & 0,028 & 0 & FEVEREIRO & 0 & 214 & 0,0288 & 0,192587674 \\
\hline MARÇO & 15 & 15 & 0,0243 & 0,011389896 & MARÇO & 0 & 214 & 0,0208 & 0,139091098 \\
\hline ABRIL & 5 & 20 & 0,0238 & 0,014874048 & ABRIL & 0 & 214 & 0,0198 & 0,132404026 \\
\hline MAIO & 65 & 85 & 0,0341 & 0,090572328 & MAIO & 0 & 214 & 0,027 & 0,180550944 \\
\hline JUNHO & 35 & 120 & 0,0506 & 0,189737856 & JNHO & 0 & 214 & 0,0341 & 0,228029155 \\
\hline JULHO & 51 & 171 & 0,0435 & 0,232438248 & JLLHO & 0 & 214 & 0,0308 & 0,205961818 \\
\hline AGOSTO & 38 & 209 & 0,0774 & 0,505486397 & AGOSTO & 0 & 214 & 0,0301 & 0,201280867 \\
\hline SETEMBRO & 5 & 214 & 0,0907 & 0,60651743 & SETEMBRO & 0 & 214 & 0,0273 & 0,182557066 \\
\hline OUTUBRO & 0 & 214 & 0,0817 & 0,546333782 & OUTUBRO & 0 & 214 & 0,035 & 0,23404752 \\
\hline NOVEMBRO & 0 & 214 & 0,0869 & 0,581106557 & NOVEMBRO & 0 & 214 & 0,0356 & 0,238059763 \\
\hline \multirow[t]{2}{*}{ DEZEMBRO } & 0 & 214 & 0,0532 & 0,35575223 & DEZEMBRO & 0 & 214 & 0,0349 & 0,233378813 \\
\hline & & & & 3,134208773 & & & & & 2,343150029 \\
\hline 2012 & Fase de uso & & $(\mathrm{tCO} 2 \mathrm{MWh})$ & & 2013 & Fase de uso & \multicolumn{3}{|c|}{ Média anual (tCO2/MWh) } \\
\hline & CPUS CONFIGURAÇÃO 2 & AGREGADO & 0,0653 & $\mathrm{CO} 2 \mathrm{eg}(\mathrm{t})$ & & CPUS CONFIGURACÃO 2 & AGREGADO & 0,09445 & CO2eq(t) \\
\hline MÉS & & & Fator Médio Mensal & & MÊS & & & Mensal & \\
\hline JANEIRO & 0 & 214 & 0,0294 & 0,196599917 & JANEIRO & 0 & 484 & 0,1151 & 1,740776083 \\
\hline FEVEREIRO & 0 & 214 & 0,0322 & 0,215323718 & FEVEREIRO & 0 & 484 & 0,109 & 1,648519488 \\
\hline MARÇO & 90 & 304 & 0,0405 & 0,384725376 & MARCOO & 0 & 484 & 0,0981 & 1,483667539 \\
\hline ABRII & 60 & 364 & 0,0642 & 0,730228262 & ABRIL & 0 & 484 & 0,0959 & 1,450394669 \\
\hline MAIO & 70 & 434 & 0,062 & 0,840821184 & MAIO & 6 & 490 & 0,1151 & 1,762355952 \\
\hline JUNHO & 20 & 454 & 0,0522 & 0,740540102 & JUNHO & 22 & 512 & 0,1079 & 1,72628951 \\
\hline JULHO & 0 & 454 & 0,0394 & 0,558951725 & JULHO & 11 & 523 & 0,0838 & 1,369518595 \\
\hline AGOSTO & 10 & 464 & 0,046 & 0,666957312 & AGOSTO & 0 & 523 & 0,08330 & 1,361347243 \\
\hline SETEMBRO & 0 & 464 & 0,0783 & 1,135277338 & SETEMBRO & 11 & 534 & 0,08400 & 1,401660288 \\
\hline OUTUBRO & 20 & 484 & 0,0984 & 1,488204749 & OUTUBRO & 0 & 534 & 0,08310 & 1,386642499 \\
\hline NOVEMBRO & 0 & 484 & 0,1247 & 1,88596679 & NOVEMBRO & 0 & 534 & 0,09300 & 1,551838176 \\
\hline \multirow[t]{2}{*}{ DEZEMBRO } & 0 & 484 & 0,1168 & 1,766486938 & DEZEMBRO & 0 & 534 & 0,08410 & 1,403328931 \\
\hline & & & & 10,61008341 & & & & & 18,28633897 \\
\hline
\end{tabular}


APÊNDICE K - Emissões projetadas dos equipamentos da configuração 2 de 2014 a 2017

\begin{tabular}{|c|c|c|c|c|c|c|c|c|c|}
\hline \multirow[t]{2}{*}{2014} & \multirow{2}{*}{$\begin{array}{c}\text { Fase de uso } \\
\text { CPUS CONFIGURAÇÃO } 2\end{array}$} & \multicolumn{3}{|c|}{ Média anual ( $\mathrm{tCO} / \mathrm{MWh}$ ) } & \multirow[t]{2}{*}{2015} & \multirow{2}{*}{$\begin{array}{c}\text { Fase de uso } \\
\text { CPUS CONFIGURAÇÃO } 2\end{array}$} & \multicolumn{3}{|c|}{ Média anual (tCO2/MWh) } \\
\hline & & AGREGADO & & CO2eq $(\mathrm{t})$ & & & AGREGADO & & CO2eq $(\mathrm{t})$ \\
\hline MÊS & & & Mensal & & MÊS & & & Mensal & \\
\hline JANEIRO & 0 & 534 & 0,05690 & 0,949457981 & JANEIRO & 0 & 320 & 0,06713 & 0,671290368 \\
\hline FEVEREIRO & 0 & 534 & 0,05667 & 0,94556448 & FEVEREIRO & 0 & 320 & 0,06596 & 0,659513344 \\
\hline MARÇO & 0 & 534 & 0,05313 & 0,886605754 & MARÇO & 0 & 320 & 0,06391 & 0,639070208 \\
\hline ABRIL & 0 & 519 & 0,05997 & 0,97252213 & ABRIL & 0 & 320 & 0,07336 & 0,733508608 \\
\hline MAIO & 0 & 514 & 0,06803 & 1,092715478 & MAIO & 0 & 320 & 0,08171 & 0,817058816 \\
\hline JUNHO & 0 & 449 & 0,06473 & 0,908231453 & JUNHO & 0 & 320 & 0,07494 & 0,74939648 \\
\hline JULHO & 0 & 414 & 0,05133 & 0,664082496 & JULHO & 0 & 320 & 0,05818 & 0,581740544 \\
\hline AGOSTO & 0 & 363 & 0,05313 & 0,602692675 & AGOSTO & 0 & 320 & 0,06081 & 0,608072192 \\
\hline SETEMBRO & 0 & 325 & 0,06320 & 0,64183392 & SETEMBRO & 0 & 320 & 0,07517 & 0,75161856 \\
\hline OUTUBRO & 0 & 320 & 0,07217 & 0,72162048 & OUTUBRO & 0 & 320 & 0,08456 & 0,84550144 \\
\hline NOVEMBRO & 0 & 320 & 0,08443 & 0,844279296 & NOVEMBRO & 0 & 320 & 0,10071 & 1,007046656 \\
\hline \multirow[t]{2}{*}{ DEZEMBRO } & 0 & 320 & 0,07860 & 0,785949696 & DEZEMBRO & 0 & 320 & 0,09317 & 0,93160704 \\
\hline & & & & 10,01555584 & & & & & 8,995424256 \\
\hline 2016 & Fase de uso & \multicolumn{3}{|c|}{ Média anual (tCO2/MWh) } & 2017 & Fase de uso & \multicolumn{3}{|c|}{ Média anual (tCO2/MWh) } \\
\hline & CPUS CONFIGURAÇÃO 2 & AGREGADO & & CO2eq $(\mathrm{t})$ & & CPUS CONFIGURAÇÃO 2 & AGREGADO & & CO2eq(t) \\
\hline MÊS & & & Mensal & & MÊS & & & Mensal & \\
\hline JANEIRO & 0 & 320 & 0,07971 & 0,797060096 & JANEIRO & 0 & 50 & 0,06791 & 0,106110107 \\
\hline FEVEREIRO & 0 & 320 & 0,07721 & 0,772024661 & FEVEREIRO & 0 & 50 & 0,06661 & 0,104071271 \\
\hline MARÇO & 0 & 320 & 0,07171 & 0,717102251 & MARÇO & 0 & 50 & 0,06292 & 0,098305822 \\
\hline ABRIL & 0 & 230 & 0,07641 & 0,549143093 & ABRIL & 0 & 50 & 0,06991 & 0,109227191 \\
\hline MAIO & 0 & 170 & 0,08828 & 0,468965355 & MAIO & 0 & 50 & 0,07934 & 0,123963902 \\
\hline JUNHO & 0 & 100 & 0,08253 & 0,257877013 & JUNHO & 0 & 44 & 0,07407 & 0,101836846 \\
\hline JULHO & 0 & 80 & 0,06444 & 0,161082283 & JULHO & 0 & 22 & 0,05798 & 0,039860566 \\
\hline AGOSTO & 0 & 80 & 0,06575 & 0,164359851 & AGOSTO & 0 & 11 & 0,05990 & 0,020588458 \\
\hline SETEMBRO & 0 & 70 & 0,07412 & 0,162131984 & SETEMBRO & 0 & 11 & 0,07083 & 0,024346127 \\
\hline OUTUBRO & 0 & 70 & 0,07994 & 0,174859179 & OUTUBRO & 0 & 0 & 0,07889 & 0 \\
\hline NOVEMBRO & 0 & 50 & 0,09271 & 0,144857627 & NOVEMBRO & 0 & 0 & 0,09262 & 0 \\
\hline \multirow[t]{2}{*}{ DEZEMBRO } & 0 & 50 & 0,08529 & 0,13325536 & DEZEMBRO & 0 & 0 & 0,08569 & 0 \\
\hline & & & & 4,502718752 & & & & & 0,728310291 \\
\hline
\end{tabular}


ANEXO A - Fator Médio Mensal para inventários corporativos entre 2006 e 2013

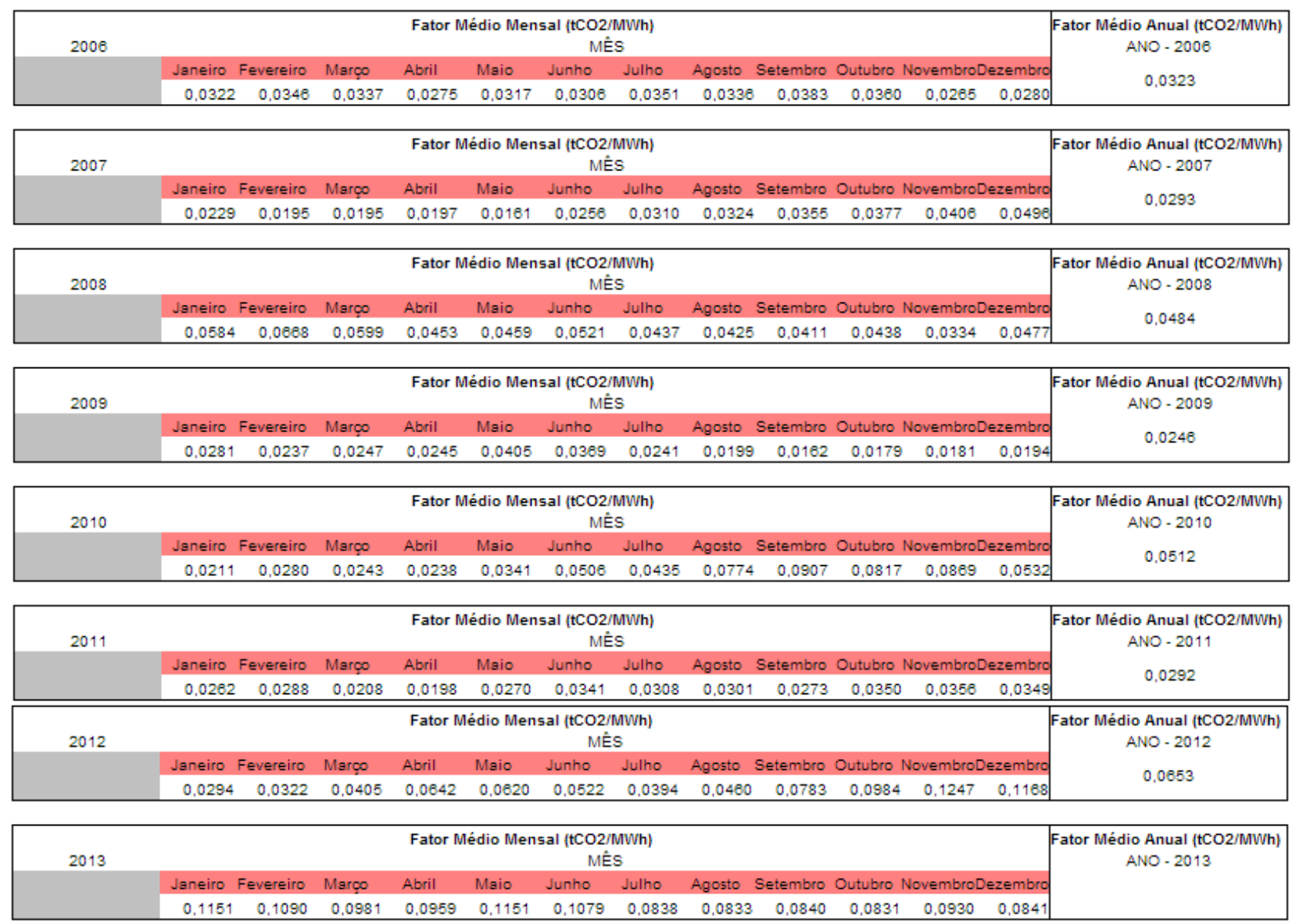

Fonte: Ministério da Ciência, Tecnologia e Inovação (2014) 